\title{
LEGAL TRANSPLANTS: WORD- BUILDING AND WORD-BORROWING IN SLAVIC AND SOUTH PACIFIC LEGAL DISCOURSE
}

\author{
Nigel J Jamieson*
}

The Slavic and South Pacific languages and legal systems are geographically distant from each other. However this paper argues that similar equivocally progressive or regressive changes operate in each with critical, and often controversial, consequences for lawyers, linguists and all others engaged in communicative enterprise. This article explores those issues and concludes with proposing a six-point model for the successful working of legal transplants.

Thomas Reed Powell used to say that if you can think about something that is related to something else without thinking about the thing to which it is related, then you have the legal mind.

Lon L Fuller The Morality of Law (Yale University Press, New Haven, 1964) at 4.

At best, what can be displaced from one jurisdiction to another is, literally, a meaningless form of words. To claim more is to claim too much. In any meaning-ful sense of the term, 'legal transplants', therefore, cannot happen.

Pierre Legrand "The Impossibility of 'Legal Transplants"' (1997) 4 MJ 111 at 120.

\section{INTRODUCTION}

Some languages, like some legal systems, are very much on the move. It is as if these languages and legal systems - as Kupe ${ }^{1}$ said of these islands of Aotearoa - are still actively in process of

* Senior Lecturer in Law, University of Otago, Dunedin, New Zealand. The author, without avoiding his full responsibility for every shortcoming in this article, acknowledges his indebtedness to both Kim Economides, Simon Currie and anonymous referees, for referring him to seminal papers and sources otherwise remaining unreferenced or overlooked.

1 Kupe, on being asked after returning home to Hawaikii why he had not named Aotearoa after an earlier Hawaikii, replied that he preferred "the warm [and presumably more dynamic] breast of the new land to the cold breast of the old land": See AW Reed A Treasury of Māori Exploration (H \& AW Reed, Wellington, 1977) at 24 . 
creation. In the midst of this apparently creative process, however, there may be linguists and lawyers who worry that these rapidly moving languages and legal systems are not so much developing and evolving (invariably a slow process over time) as that they are devolving and degenerating with the rapidity of entropic decline. As far apart as Slavic and South Pacific languages and legal systems may appear from each other, somewhat the same equivocally progressive or regressive changes operate in each of these apparently remote cultures with critical consequences for lawyers, linguists, and littérateurs engaged in every form of communicative enterprise.

At the widest possible level of lawmaking this crisis of communication is most manifest in the controversy over legal transplants. At the narrowest level of linguistic change, the same crisis (for both law and language) is documented in loanwords or word-borrowings as well as by no less frequent word-building. Despite the extent to which both the English and Polynesian languages in the South Pacific rely on word-building to evince conceptual change only a fraction of the academic attention in Slavic circles devoted to slovoobrazovaniye or word-building can be found among academics in the South Pacific.

Rather than import the Slavic concept of slovoobrazovaniye over-hastily as a template for the South Pacific and, thus, risk what could prove to be yet another culturally burdensome legal transplant, we shall honour the bigness of apparently bright ideas by according them caution. As with glasnost and perestroika, not everything that any government is in process of doing can be rendered transparently see-through and perennial restructuring ultimately indicates only governmental dithering and lack of direction since no successive structure after the sudden demise of so many earlier structures can be considered to be of any account. ${ }^{2}$

For the purposes of this paper, we shall investigate more fully the aboriginal metaphysics of linguistic-legal change. We briefly acknowledge our eventual aim of establishing with more precision, first the close dependency of law on language; secondly, the degree to which much the

2 The entire New Zealand statute book over the past two decades testifies to massive restructuring, ongoing not only macroscopically in its communicative layout, format, form, and function, but also microscopically in so far as almost every enactment can be classified either as an instance of governmental restructuring (whether token or true) or as an instance purporting to effectuate transparency (whether real or imagined). More often than not, the enactments manifest a Slavic combination of both perestroika and glasnost, so that restructuring is done in the name of transparency, or else on the basis that transparency requires or justifies restructuring. As with the greatly controversial expression of "life-sentence" in the field of criminal justice, a great deal of redefining of terms (the restructuring of language frequently at the expense of already innate transparency) diminishes the authority of law. As we shall see later, the legislative redefinition of language can be viewed as a minimalist form of lingual-legal transplant of an intra-specific nature. Recurring and revisited enactments of purportedly "final settlement", tabula rasa revisionist legislation of large areas of the legal system, and the renewal of recently legislated controversies as once again raised over our foreshore and seabed law, seem only to exacerbate the sense of jurisprudential uncertainty. More than a few Sovietologists have remarked ironically on the deleterious effect on the West (transmuted through ideologies of perestroika and glasnost) of the fall of communism in the East. 
same legal and linguistic problems are mirrored in (or are reflected by) often widely different cultures and jurisdictions; thirdly, the degree to which some of the controversy surrounding the topic of legal transplants is self-generated by the language we employ of the topic; fourthly, the extent to which legal transplants are of far more common occurrence than they would be recognisable, even within comparative law and from a purely legal point of view; fifthly, the linguistic care and conceptual caution required to effectuate any purposeful legal transplant; and finally, overall, the extent to which law-makers when pre-occupied with their own legal endeavour are apt to overlook the essential life-line of language on which the success of their own legal endeavour depends.

\section{THE METAPHYSICS OF LINGUISTIC-LEGAL CHANGE}

Since any such change in law or language could be either developmental or degenerative, how then would one formulate a due process for both quantifying and evaluating legal and linguistic change? The process, in being definitively Whorfian ${ }^{3}$ is bound to be self-referential, since one's world outlook on both law and language is largely decided by one's own legal, as well as linguistic, upbringing. Not only is it the case that one's legal and linguistic upbringing determines one's own world outlook, but in determining where one's legal and linguistic upbringing first came from, we can only infer that it arose from the same already established world outlook from which was derived one's own legal and linguistic upbringing.

This self-defining world outlook, constrained and fenced in as it is by what we own up to as being our own language and laws, customs and culture, remains definitively self-referential, unless it can extend itself to a wider appreciation of other worldviews. The key to such extension lies in learning about, and immersing oneself in, the languages, laws, customs, and cultures of other world outlooks.

Once again, both liberally understood and traditionally recognised, this comparative process has been regarded as valid either educationally for its own sake, or for encouraging a mutual respect, understanding, and toleration for the strengths and weaknesses of divergent worldviews. The resulting comprehensive account of worldviews gives some measure of evaluation, however relative, to what but for the comparative process would be solely one's own self-referential and unextended worldview. Likewise, including one's own worldview when compared contextually with other worldviews, one may seek to develop a less relative and more absolute measure of all worldviews. This process, when focused on law and done either as a relative measure by way of extending one's own worldview, or to promote understanding, evaluation and unbiased toleration of

3 For the Sapir-Whorf (sometimes Sapir-Whorf-de Saussure) hypothesis see John B Carroll (ed) Language, Thought, and Reality: Selected Works of Benjamin Lee Whorf (MIT Press, Cambridge (Mass), 1956); and George Steiner "Linguistics and Literature" in Noel Minnis (ed) Linguistics at Large (Paladin, London, 1973 ) at 130. For the purposes of this paper in its dealing with Slavic thought, note that the concept of world outlook, derived from nineteenth century philosophic thought, is common to both Slavic (mirovozzryeniye) and Western thought. 
different worldviews, or else just educationally for its own sake, could be called the pure theory of comparative law.

Nevertheless, this same comparative process has also been promoted more radically and strategically from time to time as a means of achieving a unified and uniform single world outlook. It needs be noted, as a matter of theoretical concern, that this strategically activated use of comparative law not only runs counter to the pure theory of comparative law, but also runs counter to achieving any means of measuring divergent world-views. By reducing the many to one, and thereby doing away with comparative law as a means to some other but perhaps political, governmental, cultural, and even racist or religious end, obviously runs counter to the pursuit of comparative law educationally for its own sake.

Most critical of all the consequences attributable to any such unified theory of comparative law when directed towards some strategically extraneous end, however, is the effect of its fundamental opposition to respecting and preserving the identity and character of differently fragmented and less than unified systems of law. As distinct from the pure theory of comparative law, which revels in the almost biological diversity of different legal systems, this mission-motivated, purpose-driven, and teleological aspiration invigorates what could be termed the strategic theory of comparative law.

The paradox of any such strategic theory of comparative law is that the theory will eliminate in part and eventually in whole first the resources, and thus the entire study of comparative law. Even if this uniform outcome could be argued on Darwinist terms to denote the survival of the fittest, this survival of the fittest of all possible legal systems explains not the origin but the demise of all species of legal system other than the conjecturally fittest one. Apart from securing some extraneously strategic end, could the resulting loss of legal systems, each by its own diversity, having developed appropriate to its own nation, race, culture, politics, and government, be genuinely considered, on behalf of all existing legal systems, to be a fitting end to comparative law?

Likewise, apart from the social science debate as to the divergent, rather than convergent, effect of global influence, how can strategically inclined comparative lawyers fail to see, on any straight theory of global convergence aiming to achieve a unified and uniform single world outlook on law, that this one-size-fits-all worldview is bound to bring about first a restricted gene-pool of raw resources, and secondly, as within the present European Union, ${ }^{4}$ either a complacent indulgence, a fractious intolerance, or an apathetic lassitude, and finally, and surely for the worse, an end to all comparative law?

4 "The imperatives of a specific Anglo-American economic culture as against a specific Continental one will bring about an even more fundamental reconstruction of good faith under the new conditions. This is why I think that in spite of all benign intentions towards an 'Ever Closing Union', attempts at unifying European contract law will result in new cleavages": Gunther Teubner "Legal Irritants: Good Faith in British Law or How Unifying Law Ends Up in New Divergences" (1998) 61 M LR 11 at 12. 


\section{LEGAL SYSTEMS AND LANGUAGE SYSTEMS}

We began by commenting on how some languages, like some legal systems, are seen to be very much on the move. It seems as if such legal and linguistic systems are still in process of creation, yet some linguists and lawyers worry that such systems, instead of evolving, are in entropic decline. This is one of the many converging points of law and linguistics at which it is apt to remind ourselves of what Thomas Reed Powell famously said "that if you can think about something that is related to something else without thinking about the thing to which it is related, then you have the legal mind". 5 Nevertheless, perhaps word-borrowing and word-building might provide an insight into treating the problem of legal transplants - perhaps even providing a paradigm for the efficaciousness of legal transplants.

The law and its own language are inextricably intertwined; yet although we admit of the law as being intimately related to language, such is the narrow focus of the legal mind as to think almost entirely of the law itself and little or nothing of the language to which the law is not only intimately related but also on which the law is operationally reliant and functionally dependent. We are unconscious of the degree to which linguistic rules are existentially employed to express legal rules, the extent to which rules of grammar enforce rules of law, and the forcefulness with which general semantics underlies and often determines legal meaning. As for Watson's cheerful optimism in declaring legal transplants to be "the most fertile source of development", ${ }^{6}$ that optimism depends on the autonomy of law as if it were entirely unrelated to language, morals, politics, and culture generally.

This tall order of legal autonomy at a globally macroscopic level is not borne out even at the most basic, yet trivially detailed, of microscopic levels. Certainly for most African countries at an everyday anthropological level, the wholesale reception (or, more accurately, expansion) ${ }^{7}$ of English jurisprudence would prove a fractious irritant. ${ }^{8}$ The same failed outcome would be attributed to the

$5 \quad$ As quoted in Lon L Fuller Morality of Law (Yale University Press, New Haven, 1964) at 4.

6 Alan Watson Legal Transplants: An Approach to Comparative Law (University Press of Virginia, Charlottsville, 1974) at 95; see also Alan Watson "Legal Transplants and Law Reform" (1976) 92 LQR 79; and Alan Watson "Aspects of Reception of Law" (1996) 44 Am J Comp L 335.

7 Expansion rather than reception is the word of preferred choice by which to distinguish the differential extension of the world's "two great rival systems", Roman or Civil Law and English or Common Law, in deciding which, if either, will "prevail over the other": James Bryce "The Extension of Roman and English Law Throughout the World" in Association of American Law Schools (eds) Select Essays on AngloAmerican Legal History (Wildy \& Sons, London, 1968) vol 1574 at 619.

8 It will be recalled that New Zealand's first Attorney-General, William Swainson, was threatened with dismissal (by Lord Stanley, Secretary of State for the Colonial Office) for debating the extent to which English law would be applicable to New Zealand: "Mr Swainson must be apprised that neither he nor any other person who shall oppose this fundamental principle of your Government [as to sovereignty and laws] can be permitted to act any longer as a Public Officer under the Queen's Commission". See NA Foden New Zealand Legal History (1642-1842) (Sweet \& Maxwell, Wellington, 1965) at 94-101. 
introduction of legal codes to implement technical assistance programmes in Latin America ${ }^{9}$ as in Africa and, to a lesser extent, in Asia where Lex Americana would prove no more viable than Lex Britannica. ${ }^{10}$ Even just on the linguistic issue, no seriously committed translator would dispute Hoffman's views ${ }^{11}$ that "in order to translate a language, or a text, without changing its meaning, one would have to transport its audience as well"; that even "to transport a single word without distortion, one would have to transport the entire language around it"; and that "you can't transport human meanings whole from one culture to another any more than you can transliterate a text." On no more than just the linguistic issue, therefore, the process of actually implanting the legal transplant proves to be, as Legrand points out, "impossible". ${ }^{12}$

The law is likewise subject to the processes of categorization and predication by which Aristotelian logic indoctrinates the discourse of law with a second-order linguistic awareness of whatever processes of categorization and predication are systemic to its language. Consequently, what we conceive of as being legal transplants will be truly or falsely conveyed by the language we use of them so that for both communicating as well as conceiving of legal transplants our language and law can become so inextricably intertwined as to make issues of nomenclature take the place of what they most essentially are.

\section{THE LEGAL TRANSPLANT AS A TOPOS}

What makes for a topos or topic? There is nothing in comparative law so fast-moving at the moment than both the language and linguistic theory, and in consequence, both the legal theory and the law, for whatever we have grown accustomed to call, legislatively implement as legal transplants. At the same time, there is no topic of comparative law more theoretically dynamic and jurisprudentially controversial than this same topic as to how legal transplants should themselves be

9 For "the collapse of faith" in "one of the most glamorous areas of applied economics" see David M Trubeck and Mark Galanter "Scholars in Self-Estrangement: Some Reflections on the Crisis in Law and Development Studies in the United States" [1974] Wisconsin LR 1062 at 1065 and 1069; for the "law and development movement in the United States ... [being] now almost dead" see Francis G Synder's book review of James A Gardner Legal Imperialism: American Lawyers and Foreign Aid in Latin America (University of Wisconsin Press, Madison, 1980); Francis G Synder "The Failure of 'Law and Development'" [1982] Wisconsin LR 373; Brian Z Tamanaha "Review Article: The Lessons of Law-and-Development Studies" (1995) 89 Am J Comp L 470; John H Merryman "Comparative Law and Social Change: On the Origins, Style, Decline \& Revival of the Law and Development Movement" (1977) 25 Am J Comp L 457; and Daniel Berkowitz, Katharina Pistor and Jean-Francois Richard "The Transplant Effect" (2003) 51 Am J Comp L 163.

10 See Jacques de Lisle "Lex Americana: United States Legal Assistance, American Legal Models, and Legal Change in the Post-Communist World and Beyond" (1999) 20 U Pa J Int'l Econ L 179.

11 Eva Hoffman Lost in Translation: A Life in a New Language (Minerva, London, 1991) at 275, 272, 175 respectively.

12 Pierre Legrand "The Impossibility of 'Legal Transplants'" (1997) 4 MJ 111 at 116-119. 
regarded, and as to whether any legislative vocation should be claimed and authorised for them by comparative law. On the one hand, legal transplants have been extolled, most modernly - since modernist legal theory ${ }^{13}$ plays a large part in underpinning the affirmative support for legal transplants - as being, to quote again the words of their chief proponent in comparative law, its "most fertile source of development in comparative law". ${ }^{14}$ Some modernists ${ }^{15}$ propound "a method for transplants", whereas more cautious commentators, by considering "the logic of legal transplants," 16 point to the strictures of Savigny, Hegal, Montesquieu, Marx, Jhering, Pound, and others, against their use, go so far as to fiercely oppose transplants as the product of a "bankrupt style of scholarship" that "scorns ideas and fixes its gaze lovingly on the black-letter rules of private law."17

Although transplant theory has been credibly allied to both modernist and dependency theory ${ }^{18}$ and to language theory, it would be doubtful to debunk any part of this debate for being no more an instance of radical versus conservative thinking or of modernist versus classicist thought ${ }^{19}$ any more than to debunk the debate for resting on merely different ways of using words. On all theoretical fronts, but most particularly on legal theory and language theory, the debate increasingly draws in and extends its arena to ever-widening issues of anthropology, sociology, and psychology as well as of law, language, and logic in their widest of jurisprudential and cultural contexts.

The ever-widening debate has demonstrated many disasters provoked by legal transplants in practice, ${ }^{20}$ while on behalf of those who champion transplants, ${ }^{21}$ it has promoted their deeper and

13 See Tamanaha, above $\mathrm{n}$ 9, at 471-477.

14 Alan Watson, above n 6, at 30.

15 JWF Allison A Continental Distinction in the Common Law (Clarendon Press, Oxford, 1996) at 4-41.

16 William Ewald "Comparative Jurisprudence (II): The Logic of Legal Transplants" (1995) 43 Am J Comp L 489 at 489.

17 Ibid, at 492 .

18 See Tamanaha, above $n$ 9, at 471-477.

19 Although the debate both provokes as well as clarifies innate differences of world view between Civil lawyers and Common lawyers, and between public lawyers and private lawyers, together with attempts, both sociological and methodological, to synthesise the different views. For a very perceptive perspective on these historical and comparative issues now to the forefront of English public law see Allison, above $\mathrm{n} 15$.

20 Robert B Seidman State, Law, and Development (Croom Helm, London, 1978) at 34.

21 Alan Watson Society and Legal Change (Scottish Academic Press, Edinburgh, 1977); for "Professor Watson's book [being] a missed opportunity" see Richard L Abel "Law as Lag: Inertia as a Social Theory of Law" (1981-1982) 80 Michigan LR 785 at 807; see also Alan Watson "Aspects of Reception of Law" (1996) 44 Am J Comp L 335; and for a more complete bibliography of Watson's earlier contributions to this debate see Ewald, above n 16, at fn 1. 
more detailed consideration resulting in "new methodological standards for sociological speculation about the nature of law".22

Nevertheless, the opposition to transplants is of significantly longer tenure. Legal transplants have been long decried as "unlikely to suit" and a "grand hazard". ${ }^{23}$ They "practically never work", according to Pound; ${ }^{24}$ or else, when transferred between different power structures, they may "wilt and wither" according to Marsh. ${ }^{25}$ They are but "legal irritants... and "misleading metaphors", ${ }^{26}$ since for several reasons they contravene "the Law of Non-Transferability of Law". ${ }^{27}$ Accordingly, they remain basically "untransferable" and, as so-called transplants, constitute "no such thing". ${ }^{28}$ As Greenberg, paraphrasing Sumner's Folkways, ${ }^{29}$ writes, so also "stateways cannot change folkways". ${ }^{30}$ Legal transplants simply "cannot happen ... precariously based [as they are] on analogies, on mechanical analogies ..." .31

Languages demonstrate both form and function. Some languages, especially those that rely on signs, are very formal, almost ritualistic in their required conformity. Some of that same semiotic conformity that may be retained for such as spelling, also extends to grammar and style in language, and to legal form for its evidentiary function in legal system. Thus, all languages necessarily demonstrate a static component on which different levels of communicative function rely for their

22 Ewald, above n 16, at 509.

23 Charles de Montesquieu The Spirit of the Laws (Cambridge University Press, Cambridge, 1989) bk I, at 8.

24 E Pound Social Control Through Law (Yale University Press, New Haven, 1942); reaffirmed also by Seidman, above n 20, at 34 .

25 Norman S Marsh "Comparative Law and Law Reform" (1977) 41 Rabel Zeitschrift fur Auslandisches und Internationales Privatrecht 649 at 664.

26 Watson, above n 6, at 30 .

27 Seidman, above n 20, at 29-48; Jack A Hiller "Language, Law, Sports and Culture: The Transferability or Non-Transferability of Words, Lifestyles, and Attitudes Through Law" (1978) 12 Val U L 433 for the "Law of the Non-Transferability of Law".

28 Legrand, above n 12.

29 "... legislation cannot make mores": William Graham Sumner Folkways: A study of the sociological importance of usages, manners, customs, mores and, and morals (Dover Publications, New York, 1959) at 77.

30 Jack Greenberg Race Relations and American Law (Columbia University Press, New York, 1959) at 2.

31 Legrand, above n 12. 
certainty of expression. For its time-binding function ${ }^{32}$ - maintaining constancy and continuity over time - the law relies heavily on this static component.

Most living and still developing languages, nevertheless, continue to engage in creative effort represented at least by borrowing if not by word-building. Some languages are more active wordbuilders than others; just as some languages are more active borrowers than others. These are the dynamic languages as opposed to the static or dying and declining languages. ${ }^{33}$ Because wordbuilding in particular is more inherently indicative of the creative urge than is word-borrowing, word-building stands more obviously for linguistic development rather than for linguistic decline. The same equation, building for one's own legal system rather than borrowing from others, will be seen to account more obviously for creativity in law-making.

Some fast-moving languages are relatively active only in being the more passive recipients of linguistic words, usages, and concepts from other languages; whereas those other languages from which the borrowings are made are the more obviously dynamic transmitters. The same goes for all the different "shapes and sizes" 34 for legal transplants. Moreover, not only do the "transplants come in all shapes and sizes [but] one may think also of an imposed reception, solicited imposition, penetration, infiltration, crypto-reception, inoculation and so-on". ${ }^{35}$ In the same way as linguists worry over foreign language borrowings, comparative lawyers, from Montesquieu ${ }^{36}$ to KahnFreund ${ }^{37}$ and beyond, ${ }^{38}$ have expressed anxiety over the problems of legal transplantation. For our own New Zealand jurisdiction, the present author has deplored the glib and unthinking plagiarism often associated with copycat legislation. ${ }^{39}$ Such strictures go to the substantive and conceptual issues raised or overlooked in the legislative process. These issues arise or are overlooked as much from downplaying the role of language in law as from thinking that the same legal text or formula

32 The concept of time-binding is indebted to Alfred Korzybskii Science and Sanity; an Introduction to NonAristotelian Systems and General Semantics (The International Non-aristotelian Library Publishing Company, New York, 1933).

33 As for the Russian language, "[n]ew words have been created not merely by the exploitation of the wordforming potentialities of the Russian language system itself but also, and to a very considerable extent, by the acceptance of foreign words or the fashioning of foreign words on the basis of foreign models": Robert Auty "The Russian Language" in Robert Auty and Dmitri Obolensky (eds) An Introduction to Russian Language and Literature (Cambridge University Press, Cambridge, 1977) 1 at 29.

34 Watson, above n 6 , at 30 .

35 Ibid.

36 Montesquieu, above n 23.

37 O Kahn-Freund "On Uses and Misuses of Comparative Law" (1973) 36 MLR 2.

38 See Legrand, above n 12; Seidman, above n 20; and Hiller above n 28.

39 Nigel J Jamieson "The new look Legislation" [1991] NZLJ 24; Nigel Jamieson "Legislation through the Millennial Looking Glass" (2000) 9 Otago LR 713. 
can operate out of the cultural context in which it was seen to serve its original legal function. Communicating between different legal systems requires expertise in comparative law as much as communicating between different languages needs expert translators.

\section{THE LANGUAGE OF LEGAL TRANSPLANTS}

Already, such is the power and often even also the tyranny of language, ${ }^{40}$ that the words we use, such as legal transplant in comparative law, and loanword in linguistics, conceptually cause problems. We ought to keep in mind, as we are reminded by Wise, that "[t]he original French title for this topic of legal transplants is 'la circulation des modèles juridiques',"41 no less than we remind ourselves, when working with the bilingual legislation of English-French statutes, that the French version is, most usually, interpreted according to the spirit of the legislation whereas the English version is construed, more usually, in accordance with the letter of the law. ${ }^{42}$ Thus, the concept of being borrowed or loaned conveys a dispirited feeling of that which thereby remains continuingly transient, ephemeral, and always otherwise owned.

Unfortunately, the continued conveyance of this feeling of transience is completely at odds with what is looked for by way of fulfilling the process of legal transplantation. Similarly, for a legal transplant that takes root in its newly located jurisdiction, to be called and thus, regarded as exotic or alien when it is already a deeply settled and well-integrated linguistic transplant, contradicts the whole object of the process. Perhaps it is this strongly perpetuated sense of being merely transient, conveyed also by some sense of alien intrusion inherent in the concept of a legal transplant which provokes its rejection.

Will the revising, correcting, adjusting, or perfecting of the nomenclature of legal and linguistic vocabularies - away from loanwords, borrowings, and transplants- overcome the problems of corrupted acceptance or outright rejection? As if legal concepts can be isolated from legal language, Ajani $^{43}$ purposely avoids the "terminological debate" which rages both over those words and an extended vocabulary either dealing with the process of "influence", "circulation", "transference", "exportation", "importation", or else with the "reception", "rejection", "extension", or any other result of the "modelling" or "copying" process.

40 See Stuart Chase The Tyranny of Words (5th ed, Methuen, London, 1943); see also Stuart Chase and Marion Tyler Chase The Power of Words (Harcourt, New York, 1954); and Stuart Chase, Marion Tyler Chase and SI Hayakawa Language in Thought and Action (5th ed, Harcourt Brace, New York, 1990).

41 Edward M Wise "The Transplant of Legal Patterns" (1990) 38 Am J of Comp L Supplement at 1.

42 One is reminded also of the cultural dissociation of French courts from English courts over trial by jury: see Marsh, above n 25, at $650 \mathrm{fn}$ 5, quoting from A Esmein A History of Continental Criminal Procedure (Little, Brown and Company, Boston, 1913) at 462-499.

43 Gianmaria Ajani "By Chance and Prestige: Legal Transplants in Russia and Eastern Europe" (1995) 43 Am J Comp LQ 9 at 93. 


\section{DEVISING METHODOLOGIES FOR LEGAL TRANSPLANTS}

Any method, by reason of its own systemic nature, is bound to be logical, at least in exhibiting measures of independence, consistency, and comprehensiveness. In so far as legal transplants are legal, any methodology devised for their employment will account for the language, the logic, and the function of law.

The devised method may be more linguistic than legal, more legal than logical, more legal than either logical or linguistic, and with these or other variants may be more or less political, conceptual, and so on, according to the cultural context in which the legal system is expected to operate. We shall briefly discuss just a few of these variants in so far as they flow conceptually from linguistic considerations.

More substantively and conceptually than only verbally and nominally, could the extending rather than the restricting of the concept of loaning or borrowing, help to overcome these problems of corrupted acceptance or outright rejection? Suppose that the present purely botanical concept of the legal transplant were to be extended by its inclusion of also legal and linguistic implants. The concept of zoological implant imports more care for the context of location than the concept of botanical transplant accords legal transplants.

Likewise, for the different categories of both legal as well as linguistic rootstocks, as for differing linguistic and legal scions, there is also a need to develop an appreciation and recognition for the - bud, stub, whip, cleft, and awl - different types of grafting techniques that take place in both linguistics and the law. ${ }^{44}$ Even more worthy of attention is the resulting exchange of genetic characteristics that can take place through hybridization and osculation that can often take place instead of outright rejection. And since Montesquieu ${ }^{45}$ attributed so much significance to climate for its effect on the law why would we not allow and provide explicitly for the process of acclimatization, perhaps by way of transitional provisions for legal transplants?

Reciprocally, then too for the legal transplant, as that phrase can misleadingly suggest for so many legal transplants a fixed or settled permanence, which as yet they do not demonstrate, ${ }^{46}$ and

44 For also transporting, tuning, and fitting mechanisms see Esin Örücü "Law as Transposition" (2002) 51 International \& Comparative LQ 205; and for tight couplings, loose couplings, and co-evolving trajectories see Teubner, above $\mathrm{n} 4$, at 18 and 27.

45 Montesquieu, above n 23, bks XIV, XV and XVI.

46 See Ajani above n 43; Robert Sharlet "Legal Transplants and Political Mutations: The Reception of Constitutional Law in Russia and the Newly Independent States" (1998) 7 East European Constitutional Review 59; Nigel J Jamieson and Alexander Trapeznik "A Legislative (Logico-Linguistic) Analysis of the Common Law Components of the Russian Constitution" (2007) 16 Transnat'l L \& Contemp Probs 431. Some several words of caution should precede arguing outright against legal transplants from the Russian experience. In the first place as Rhyne points out (Charles S Rhyne "The Law: Russia's Greatest Weakness" (1959) 45 ABAJ 246) the law is often still just that for Russians - their greatest weakness - although, despite the demise of the Soviet Union, this persists in no less intricate ways for the new Russian Federation 
which in their own transmuted context of comparative law they may never come to express, the same corrective conceptual extension and remedial linguistic device of implant may be employed. Somehow semantically, implants conceive of a need for more personal and tender loving care and attention.

Likewise for the concept of the legal transplant, some more purposive concept of the legal transplant (perhaps as an implant) has much to reveal about its correlative linguistic transplant. For this wider purpose, the concept of legal transplants for comparative law as seen in terms of competing theories derived from different conceptual commitments to legal autonomy, culture, and societal endeavour, has much by which to cross-fertilize the linguistic concept of loanwords with the legal concept of transplants to achieve the best possible outcome for each.

This is dealt with most fully, and, (as needs be) metaphysically, by Steven Heim in his paper on predicting the viability of legal transplants. ${ }^{47}$ Because of that most intimate of communicative relationships between law and language in their exercise of power and authority, ${ }^{48}$ this interactive research of Heim is likely to prove most useful to parallel the issue of predicting the viability and mutability of legal transplant-implants when measured against the needful viability and mutability of their correlative linguistic transplant-implants.

than for the former Union of Soviet Socialist Republics. Secondly, as Sharlet points out (Robert Sharlet "Legal Transplants and Political Mutations: The Reception of Constitutional Law in Russia and the Newly Independent States" (1998) 7 EECR 59 at 61) although "Watson's main conclusion, that 'most changes in most systems are the result of borrowing' certainly is a legitimate characterisation of Russian and NIS constitutional law', nevertheless there is good cause for caution: however alluringly the Russian and NIS cornucopia of legal transplants may be in providing plentiful academic resources, the result of most of this resource material, by transplanting the exotic into the indigenous, does so far not evoke much confidence for the transplantation process". Indeed, "the Russian gang is arguably the only Soviet institution that benefited from the collapse of the USSR" according to Stephen Handelman "The Russian 'Mafia"' (1994) 73 Foreign Affairs 83 at 87. See Mike Cormaney "RICO in Russia: Effective Control of Organized Crime or Another Empty Promise?" (1997) 7 Transnat'l L \& Contemp Probs 261 at 264-277. At the same time, if any word of caution should precede the Russian experience, for being a culturally special case for legal transplants on many legal, linguistic, logical and jurisprudential fronts (whether these transplants are upheld for being successfully, or decried for being unsuccessfully implanted or not) nevertheless this is only a more extreme instance of the same caution required for evaluating and implementing every exercise of apparently more moderate legal transplantation.

47 Steven J Heim "Predicting Legal Transplants: The Case of Servitudes in the Russian Federation" (1996) 6 Transnat'l Law \& Contemp Probs 188 for a synthetic jurisprudence by which to coordinate and reconcile two apparently incompatible theories of legal transplantation.

48 Legal authority, reliant as it is in any democracy on linguistic power, has much more need to avail itself of the dialectics of discourse by convening both classical and medieval rhetoric as well as modern linguistics and literary stylistics into law-school curricula than its present most cursory acknowledgement of advocacy allows. 
In practice, the question of viability for any legal transplant or implant is frequently decided by whether there exists a sufficiently receptive linguistic context - one that will confirm the existence of a correspondingly receptive culture - in which the legal implant or transplant can be nurtured and developed; or else that somewhere there exists, or can be made to exist, a sufficiently viable and mutable linguistic rootstock that itself can be transplanted, and to which the already developing legal transplant has been grafted. It is often scary to discover just how shallow-rooted or vulnerable to the slightest disturbance are many legal transplants beyond their own culture of origin; ${ }^{49}$ and no less scary to discover how many others grow uncontrollably rampant in diverse ways to militate against, and even defeat the whole purpose of their transplantation. ${ }^{50}$

There is yet a more fundamental question associated with the linguistic-legal relationship than either the verbal issue of borrowings for some legal transplants as well as transplants for some linguistic loanwords. This concerns the issues of linguistic forcefulness, accuracy, and precision of communication, and also the problem of cultural acceptance of, and adherence to new linguistic forms. These issues rely largely for their linguistic resolution on the systemic autonomy of a language. Partly because of this linguistic autonomy, it is no clearer that one can legislate for linguistic usage ${ }^{51}$ than, by reason of any claim to moral autonomy, one can legislate for morals or mores. ${ }^{52}$ This is the case despite linguistic enforcement always having an input into linguistic output no less than moral enforcement always exerts its own input into moral output. Nevertheless, whether inputs match outputs with the intended or unintended results for these remarkably alike legislative endeavours are extremely difficult to measure and determine - possibly being no less for the

49 For the concept of the political party, for example, the same borrowed word was used in Slavic Soviet circles but with vastly different connotative meanings than the same word functioned denotatively in English; see Nigel J Jamieson "Source and Target-Oriented Comparative Law" (1996) 44 Am J Comp 121.

50 Consider the almost Soviet proliferation of commissioners (in many ways the equivalent of the Soviet commissars) for this, that, and the next thing in New Zealand law, together with the institution of Scandinavian ombudsmen (which, apart from the novelty of that institution's first acceptance, we have never managed to assimilate, integrate, nor develop into Common Law jurisprudence except by way of fudging the responsibility and diminishing the legislative, judicial, and executive authority of those with whom the earlier responsibility and authority was understood governmentally to reside under the Common Law). For the "purchase advisor" in being the "newest kid on the block" - not that the "new kid" lasted long, see Sue Newberry and Alan Robb "Purchase Advisors" (2009) Watchdog <www.converge.org.nz>; Andrew Geddis "Purchase Advisers: New Dogs or Old Tricks?" (2009) Pundit <www.pundit.co.nz>; Maggie Tait "Private Purchase Advisors No Longer in Use" (2010) guide2.co.nz <www.guide2.co.nz> .

51 Rock lobsters for crayfish; kiwifruit for Chinese gooseberries; flammable for inflammable; and honest opinion for fair comment are just a few of the many New Zealand examples of legislating, justifiably or otherwise, for alternative linguistic usage. Indeed, these are examples of minuscule legal transplants convened in terms of both source and target translation within one and the same domestic jurisdiction.

52 See such classics as Thomas Hill Green Lectures on the Principles of Political Obligation (Longmans Green, London, 1941); Patrick Devlin The Enforcement of Morals (Oxford University Press, London, 1965); and Greenberg, above n 30, at 2; and Sumner, above n 29, at 77. 
legislative enforcement of morals than any legislative coercion for politics. This is a situation in which, with less abstraction, it is more accurate to gauge, as we can often do with more particularity, from a more specific than theoretical account of word-buildings and borrowings in the South Pacific. As a matter of comparative law, we shall risk doing so later with more particularity when concerning ourselves with the specific rather than the generic, and the substantive rather than the theoretical issues of linguistics. First, however, in the context of law and government we shall consider the use of words as weapons, often as weapons of political power borrowed, introduced, or administered from different cultures and different languages, while those who wield that linguistic power shield themselves behind the resultant ambiguity in meaning represented by the multicultural diversity of rules, laws, and customs employed to inculcate, yet as often to compromise law and order. The same reservation as to languages applies also to legal transplants, especially to the wholesale and often selfishly motivated introduction of transplants from vastly different and little understood legal contexts. When legislating for legal transplants, it ought not to be forgotten that the first principle of legislative drafting is to avoid all precedents, being distrustful even of the most obvious exemplars emanating from one's own domestic jurisdiction. Lawmaking is the contrary, not the corollary of conveyancing.

\section{THE NOT-SO-STRANGE CASE OF ALSACE-LORRAINE}

Writing of the polyglot culture of Alsace at the end of the Second World War, Helen Cooper writes of "a scenario that would have made an early medieval monarch proud ... to rule over an abundance of tongues and laws show[ing] that you were more than just a local ruler: an increase in diversity signaled an increase in power." ${ }^{53}$ Although stirring the pride of an early medieval monarch, the same scenario would doubtless inflate the breasts of both Soviet imperialists and British imperialists. More than a few historians have equated post-modern times with a return to medieval worldviews, and one wonders whether it might be more than either just the global interchange of diverse values, or else of furthering culture for its own sake that puffs the pride of domestic governments "to rule over an abundance of tongues and laws. ${ }^{54}$ Never before has the New Zealand government at all three levels of the legislature, the judiciary, and the executive - by legal transplants into legislation, foreign judgments applied in the domestic courts, and translations into overseas languages for the benefit of non-English speaking citizens - catered to such a diverse "abundance of tongues and laws."

The comparative evaluation of languages for their legal function is not only hugely relative to their respective cultures and concepts of law, but full of startling surprises for their outcomes. Thus, we may ask, what British expatriate lawyer in 1965 would have thought the target language of

53 See Helen Cooper's review of Andrew Butterfield The Familiar Enemy: Chaucer, Language and Nation in the Hundred Years War (Oxford University Press, Oxford, 2009): Helen Cooper "Writing French in English" (2010) 32(19) London Review of Books 9 at 9.

54 Ibid. 
Swahili more functionally apt than the source language of English for explicating the Common Law in Tanzania? Doubtless none other than A B Weston, the first dean of the then only law faculty in East Africa, who chose to challenge English theoretically for this conceptual function, held English as a source language to be better replaced by "native" Swahili as the language for law in Tanzania. ${ }^{55}$

Compared with supplanting Swahili for English as the language for law in Tanzania, our own granting of official status to Māori in New Zealand under the Māori Language Act 1987 would be but a hollow formality - were it not for the linguistic impetus given to Māori self-generative vocabulary as devised by the Māori Language Commission to fulfil the resurgent linguistic creativity for te Reo Māori purposed by this Act. Likewise, for law once again resonating as literature, and whether written in English or in te Reo Māori, no other source of, nor commentary on New Zealand law, quite measures up to the consistently high literary qualities of the Reports of the Waitangi Tribunal.

Nevertheless, there are some more practical consequences of te Reo Māori having received official status as an authorised language in our law courts. It logically follows that all law schools are inferentially obliged to require of their law students at least a working knowledge of te Reo Māori. Of course, as with the recent legislative extension to sign language the more official languages there are, then the less official are any of the languages. Despite every best intention, we face trouble whenever we think to legislate in an egalitarian mode for concepts giving a wider spread to uniqueness, excellence, and heightened status, no less than when we try to narrow and minimise correlative concepts that stigmatize against inabilities, disabilities, and strict responsibilities. The rule of law, especially, depends on decisively definitive categorization, and without other powerful forces, whether within or without government, can take advantage of or eventually take over democracies to usurp the rule of law. Law, like science, is bound to be rigorous, but never ruthless in its enforcement of the law.

\section{WORD-BUILDING IN THE SOUTH PACIFIC}

In giving specifics for both South Pacific and Slavic word-buildings and word-borrowings, we shall be no more able than to scratch the surface of our own country's fast-moving linguistic spectrum. Nevertheless, the first and earliest known name of our nation of New Zealand, Aotearoa in its being built up constituently from three independent kupu, namely ao, tea, and roa, which when amalgamated altogether signify our country of the long-white-cloud - is bound to take first place in any contest for a national paradigm of iconic word-building. ${ }^{56}$ Later traditions, overcoming transliteration difficulties for the transposition of New Zealand into Nu Tīrani (as New Zealand

55 See Seidman, above n 20.

56 Consider also Ao-tea-iti applied to Great Barrier Island; see Reed, above n 1 at 24. Place names in Māori, when memorialising events and happenings, invariably employ and rely on the same preliminary but essential principles of Slavic word-building. 
appears in Te Tiriti o Waitangi) would move along or glide smoothly into the analogue or homologue of Niu Tïreni (since the same kupu niu might conceivably reinvest the name with its original divination of foretelling a creative future) ${ }^{57}$

Although no more arguably official under the Māori Language Act 1987 than the re-naming of Niu Tìreni as Aotearoa, the well-intentioned change could still be considered either tokenistic or trivial or even counter-productive for being no more than politically correct. Political correctness, whether in Slavic or South Pacific circles, is frequently no more than a euphemism for sowing political confusion. Nevertheless, there are now upwards of 316 entries for the term of Aotearoa in the New Zealand Statute Book. However, most New Zealand citizens would need to rely on s 3(3) of the Alcohol Advisory Council Act 1976 to identify Kaunihera Whakatūpato Waipiro O Aotearoa as the Alcohol Advisory Council (which Council, ironically, when rendered in English, is not so termed under the Act to be of New Zealand).

There are five and more main reasons by which to explain the linguistic iconicity conveyed by Aotearoa. The kupu kaupapa of Aotearoa does so, first and most importantly, by thereby memorializing and institutionalizing our own country's autochthonous history. The written name of Aotearoa employs linguistic word-building to monumentalise the name and identity of Aotearoa. On the printed page these functions are made concrete. Virtual replication through publication on the web of what then possibly becomes in lower case merely the statute book might well diminish the authentically hard-copied authority of legislation, and in turn the iconicity of Aotearoa.

Briefly, we shall recite no more than the four remaining factors typifying both the linguistic and conceptual iconicity conveyed by Aotearoa. The second point is that by substantiating and consolidating Aotearoa's autochthonous history with geography our name integrates both space and time through a divinely inspired ${ }^{58}$ yet humanly vulnerable account of dynamic travel. Thirdly, Aotearoa provides an everyday mnemonic for the ongoing recovery of both epic as well as ontological narrative. Fourthly, it makes independent landfall, both literally and figuratively, by indicating and defining a more inclusive and national turangawaewae or place on which to make a more consolidative stand. This is the case, since, for example, Te Tiriti was not even an assumed stance for Hobson's Proclamation of British Sovereignty over the South (or Middle) Island. Fifthly, by concluding a trialing process begun by Kupe beset with many diverse and unforeseen risks confronting Aotearoa between then and now, the kupu kaupapa of Aotearoa as our national name expresses a fulfilment of our country's original and continuingly creative objectives.

The substitution of Aotearoa for Nu Tìrani, for Niu Tìreni, and increasingly for either accompanying or supplanting New Zealand itself, is not merely a linguistic move but by reason of

57 See HW Williams A Dictionary of the Māori Language (Wellington, Government Printer, 1985).

58 For Kupe's divine voice see AW Reed, above n 1, and consider the Third Covenant of the Treaty as presented and explained by missionaries as such to the Māori. 
its legislative effectuation, an example also of a legal transplant undertaken from source to target transplantation entirely within our own domestic jurisdiction. Less legislatively direct than openly substituting honest opinion for fair comment, ${ }^{59}$ but more resembling the legislative creation of a tabula rasa to supplant flammable for inflammable, rock lobsters for crayfish, or kiwifruit for Chinese gooseberries, this move, achieved more institutionally and quantitatively and has its own outcome still in the making. Nevertheless, many of the same principles apply, not only to the transplanting from one jurisdiction to another of legal transplants, but also to the supplanting of one word or concept for another word or concept within the same jurisdiction. Indeed, the very same supplanting function operates throughout the redefining of words and concepts by the interpretation section of any statute. For the purposes of any such statute, and depending on the statute's draftsmanship and the response of the judicature, the supplanted transplant of linguistic usage will be technically upheld as a valid and effective implant. Behind the scenes, however, the private history of New Zealand's Parliamentary Counsel Office records enough other instances of counsel maintaining their professional independence by refusing point-blank to re-name this that.

By now having taken the word-building that gave rise to the concept of Aotearoa for granted, we have come to consider the more apparently mechanical process of supplanting words (and concepts) for other words (and concepts). Substituting one for another set of words may still relate to the conceptual issues of word-building, but the formal and largely semiotic issues exert their own influences on the conceptual outcome. These semiotic issues introduce a need for caution.

Many instances of word-building express no more than the semiotics of continua scripta, when, as in the early days of writing, written words were run together just as quickly as they were heard pronounced. ${ }^{60}$ Thus, was never first conceived as one word, any more than were Ngongo (drink) and taha (calabash) used to build Ngongotaha (a place well-known around Rotorua); nor was "Taumata" ("brow of a hill"), "wakatangihanga" ("making music"), "koauau" ("flute"), "a" ("of"), "Tamatea" ("a well-known chief"), "pōkaiwhenua" ("widely-travelled"), "ki" ("to"), "tana" ("his"),

59 "In proceedings for defamation, the defence known before the commencement of this Act as the defence of fair comment shall, after the commencement of this Act, be known as the defence of honest opinion": Defamation Act 1992, s 9. The verbal redefinition of the defence of honest opinion as the defence of fair comment (whatever the intended conceptual consequences) is an instance of superficially linguistic, rather than of deeply substantive legal transplant. Taking place as it does within one and the same jurisdiction (and within the same sub-system of defamation) this is also an instance of intra-specific rather than inter-specific transplant.

60 Fast writers, whether by hand or on keyboard, still frequently run words together in continua scripta. A revealing parallel to the continua scripta of the earliest verbal transcription exists in early musical notation before the introduction of bar lines. The process of doing away with bar-lines has been regressively revived in modern music, where changes of rhythm are so frequent, syncopated, or distorted, or else the timing is so freed as to make nonsense of bar-lines and time-signatures. The same is true of their equivalent forms for modern verse and prose, in changes of measure, metre, or verse or stanza eschew their correlative grammatical and literary forms. 
"tahu" ("beloved") conceived of nominally as in the Hawkes Bay place-name of Taumatawhakatangihangakōauauatamateapōkai

whenuakitanatahu. ${ }^{61}$ How then, according to the same strongly cultural principles of word-building, shall we interpret even just kaitiakitanga as that apparently far simpler exercise of word-building requires us to conceive legislatively of s 7(a) of the Resource Management Act 1991? One answer is to consider the way in which, as from Oxbridge in English or from EmGeU in Russian, new and innovative concepts are being created, rather than merely the same sense being conveyed by running words, or parts of words together.

\section{COMPARING THE SOUTH PACIFIC AND SLAVIC TREATMENTS OF WORD-BUILDINGS AND WORD- BORROWINGS}

Word-building is so common-common-place in Māori as to be taken for granted. Word-building is both so entrenched and explicitly studied in Slavic linguistics, that A N Tihonov's two-volume standard work ${ }^{62}$ on the subject runs to upwards of 145,000 built-up words comprising more than one and a half thousand pages of itemised fractals. This aggregative process of word-building may be illustrated best for Pākehā ${ }^{63}$ in terms of the English language.

In English our process has either shrunk or grown deficient, and this even to the point that illinformed usage has displaced the science of etymology at the highest of academic levels. ${ }^{64}$ Instances of attempted word-building, as with thankyou (just permissibly thank-you) for thank youor insofar for in so far, may never take a conceptual hold, while intermediate instances of wordbuilding may be introduced as with hyphens before being independently conceptualized in their own semantic right. This independent conceptualization of a semantic right is significant in itself for holding some amalgam of meaning more forcefully and innovatively than could be conveyed by

61 Note the function served by the habituating hyphen indicating the development of a conditioned reflex in the intermediate process of word-building between accustomed contiguous words.

62 AN Tihonov Slovoobrazovatyel'nyi Slovar' Russkovo Yazika (Russkii Yaziik, Moscow, 1990).

63 Although at odds with the fiercely reductionist move, introduced perhaps by the poet e e cummings, to reduce all and everything, including the Common Law, to lower case, we follow the present fashion of capitalising Māori and Pākehā with some misgiving. This capitalisation denotes each as belonging to different races and classes of person, rather than seeing them more appropriately as Pākehā and Māori belonging to the same iwi tahi tatou, to be thus rendered more aptly as adjectives in lower case. We baulk at using macrons for the Māori language, however, thinking that te Reo Māori, no less than Russian without any need for the learner's udaryeniye or stress-mark, is sufficiently grown up to make its own way. Likewise, by italicising Māori words and phrases in the context of another written language, we choose to confer the appropriate respect for te Reo Māori as an independent language.

64 Dictionaries, being no longer professedly prescriptive of linguistic usage, but instead now professedly descriptive of linguistic usage, in turn through the response of their readers, make usage their own measure of prescriptive correctness. 
each independent part by itself. Acquiring self-identity seems to be the key, both for wordborrowings and word-buildings, to enable neologisms to hold their place. Thus, Shakespearean lacklustre means something more than simply to lack lustre, and barefaced is far different from just baring one's face. So, too, Noah Webster's Novo-American spelling of the English language, which reduces lustre to luster is, like the Bolshevik revision of the Cyrillic alphabet (done simply because the Bolsheviks were running out of paper) an expression of no more significance than the continuing contrariness of the post-revolutionary mind.

Nevertheless, we take our word-building in English for granted - since the strength of the verb to fare-well (literally) becomes conceptually depleted when standing for no more than a figurative farewell. Likewise, a place by which to maintain a strong hold (literally) comes to stand (figuratively) for the place or stronghold from which a strong stand against opposing forces can be held. So also, to fall becomes (figuratively) landfall when falling upon land after long travelling by sea, the semantic and semiotic changes keep pace with each other, as if the matching and mating of both signs and meanings is bound to produce conceptually changing offspring.

However, as with any process of word-building, we proceed linguistically with caution, no less than when law-making by legal transplant we should proceed juristically with caution. Much done with hindsight can obliterate rather than reveal what began with foresight. Each language has its own approach to word-building. Sometimes the process may be more semiotic than semantic, at other times more semantic than semiotic. For Māori word-building as for Slavic word-building, the semantic re-conceptualisation is more frequently than not the forerunner of the final semiotic synapse. Thus, puka-puka in Māori for a book conceives of the turning leaves, the whispering from the apparently living leaves of an opening and closing book to be the rising and falling, inhaling and exhaling, of the breathing lungs with which one reads aloud the book. Unsurprisingly, therefore, the same word pukapuka stands in Māori for both lungs and book. ${ }^{65}$ What this means is that the intellectual configuration or re-configuration of the concept predates the purely nominal sign. But in this case, as so often in Māori, the sign, the sound, and the significance are drawn so poetically close since book in English, without any $b$ in Māori, is bound to become first puk-a, and thence identifiably with the way in which the lungs work, pukapuka for what is heard from a bi-lobed open book as told with the breath of the lungs in their doing the reading as the pukapuka is also being read.

Divining one's own native language, whether to find examples of indigenous word-building in English, or of loan-words say in their movement between English and Māori in a increasingly bilingual context, is most often for anyone in their native language a difficult task. Our divination is as often disadvantaged as it is advantaged by unselfconscious familiarity with our own language, as if in seeking its inherently innate aspects we were setting out as prospectors for some rare earth such

65 Nevertheless, see below n 83. 
as uranium, which, although being one of the commonest elements in the earth's crust, we nevertheless completely overlook simply because the strikingly large deposits of high-grade ore we seek, are rare. The same goes for legal transplants as for linguistic transplants - they are all around and within us, but the question remains whether we can order and control their form and function, or whether the barebones fact of the matter is that, whether as linguistic transplants or as legal transplants they control us. By that which we are inherently controlled we most obviously think of ourselves to be in full control.

\section{WORD-BORROWINGS IN THE SOUTH PACIFIC}

Loanwords, in the realm of linguistic borrowings, operate much like legal transplants in the realm of comparative law. Loanwords may, or may not settle in, depending on whether they plug a linguistic or conceptual loophole, or else whether they persist as foreign imports. ${ }^{66}$ The so-called inkhorn controversy of the 17th century, when linguistic enthusiasts (including Shakespeare) borrowed heavily from classical sources to coin new words - some such as skeleton, pneumonia and thermometer which would successfully implant usually to fill a scientific niche, but others such as nidulate (to build a nest) and expede (the opposite of impede) which would (together with Shakespearean tortive, perisive, and cadent) fail to fly - can be considered, if not closely equivalent to, at least to provide a linguistic analogue for comparative law's legal transplant controversy of our own time.

When indigenous word-building - from the Shakespearean neologisms for barefaced and lacklustre to New World neologisms for foothills, watershed, warpath, and rattlesnake - goes on to incorporate loaned elements of exotic origin, however, this incorporation is evidence of implantation rather than of merely transplantation. The implantation is not merely formal but functional, not merely linguistic but also conceptual, and this whether in terms of whole words and phrases or else prefixes and suffixes. Integration and assimilation, at least of the linguistic components, together with the recognition, adaptation, modification, and re-orientation of the indigenous context to the exotic implantation are but some among many other indicators of word-building.

Word-borrowings, rather than word-buildings, constitute the apparently bigger and more culturally obvious area of dynamic linguistic activity in today's Aotearoa. Word-borrowing, at first, despite transliterative difficulties, preponderantly from English into Māori yet now increasingly from Māori into English, is the first step towards achieving a mutual awareness, recognition, and acceptance of both languages. Of course, there are real risks, as there are with all cross-cultural activities. One risk is that instead of cross-fertilising each language, one language takes over the

66 Consider the varying degrees of indigenous assimilation attributable to what must, when generally expressed, be still inherently and collectively regarded as foreign - in the sense still expressed, for example, by the title to the Oxford Dictionary of Foreign Words and Phrases (Oxford University Press, Oxford, 1997). 
other. Worse still, another risk is that both languages, simply by their coming ever closer together, simply exhaust instead of exhilarating each other.

Between Māori and English, or between English and Māori or whether from Māori to Pākehā or Pākehā to Māori, concepts and ideas should move from one to another culture generally, the creative momentum by way of intimately cross-cultural amalgamation of both linguistic and conceptual resources is most obviously by transferred borrowings rather than by as yet any more intimate and interactive word-buildings. At the exchange-mart of interactive linguistic borrowing we then barter for different words and concepts, that will readily and accurately communicate the same or most nearly the same significance to each culture. And why should this not be so, when turangawaewae or a place to stand is pretty nearly equivalent to locus standi, and mana is pretty nigh the same as the Anglo-Saxon legal concept of wer or worth? Thus, whether for the better or worse at the legal level of the Resource Management Act 1991, we risk trading in concepts of kaitiakitanga, maataikai, or mana whenua while also daring to decide to leave the connotation of these terms to mostly Māori conceptualisation. We find that there is no completely open market for cultural exchange or interchange.

This, then, is the situation generally to be found at an exchange-mart level of language, and as often also at an exchange-mart level of law, open mutually to both Māori and Pākehā. For the most part, if the exchange and interchange is needful and practical rather than being politically corrective or pragmatically indulgent, we have a cross-cultural workface for linguistic and legal trading at which most obviously creative things are happening. Interactive word-building between two or more languages is largely a second-order or third-order activity engaged in only after the linguistic workface is working conjointly. This second-order or third-order word-building activity will nevertheless build on and incorporate the already incorporated word-building inherently incorporated in and contributed to by each of the constitutive components.

By way of illustration, we could at this point return to the linguistic paradigm for legal transplants by way of being the built-up proper name of Ao-tea-roa. This iconic place name is but one example of the way in which the proper names of places not only tell a story but also identify space with time, and time and space with people. Likewise for Pākehā, we may never appreciate either the legislative or normative input or even the overall potential output for word-building in the Māori language as against the English language, until we compare the more fully documented width and density of word-building in the Slavic languages. The same goes for loan words, and more especially, for indigenously created words for the direct importation of borrowed concepts.

First, in the free-willed arena of linguistic exportation from the South Pacific, into English and elsewhere, are such words as taboo from Tonga, with perhaps also kava, both holding currency now elsewhere from the 18th century, and vahine since the 20th century from the Tahitian, with its correlative wahine, which, together with tiki, are both earlier from Māori in the 18th century. Likewise, whare from Māori of the 18th century, no less than its more recent correlative fale from 
Samoan, provide common, everyday examples of free-willed borrowings, not just into New Zealand English but into standard English dictionaries as also into dictionaries of other languages.

Such is the present currency of these centrifugally flung linguistic transplants from the South Pacific that an understanding of their usage beyond their own linguistic origins may be presumed, if not always in every case assumed. From the point of view of both comparative linguistics, as well as being needed later for comparative law, it is critically significant to weigh up the balance of the freewilled linguistic trade both inwards and outwards from the South Pacific, before thinking to redress any imbalance by way of linguistic legislation.

Nevertheless, New Zealand culture is inherently polarised - not only as between Māori and Pākehā - but also among Pākehā in settling so far south of their cultural roots as for them to be torn between their ontological origins in the northern hemisphere and their teleological development in the southern hemisphere. Likewise, as between North Island and South Island the polarisation can be fierce enough to affect the dynamics of law, language, and logic - and so also in turn, the dynamics of governance. In the face of such polarised conflict it can be helpful to return to the particulate simplicity of the Māori language.

\section{KO WIKITORIA - THE PARTICULATE PRESENT INDICATIVE}

Before engaging in any enterprise of linguistic translation, it is worth recalling Legrand's earlier quoted caution that "[a]t best what can be displaced from one jurisdiction to another is, literally, a meaningless form of words"; from which it follows, "'legal transplants', therefore cannot happen."67 The same argumentum ad absurdum for legal transplants applies not also only to linguistic transplants, but also to all linguistic translation. With even more particularity, the argument applies both to attempts at literal translation, and to the linguistic analysis, other than for purely comparative purposes, by applying the grammatical measure appropriate only within the jurisdiction of another language. What follows, therefore, is a purely comparative approach.

First, in arguing from the known to the unknown, the most telling and explicitly obvious instance of the particle ko operating in Māori to express the present indicative - although inferentially rather than directly, since as Bauer explains "Māori has no copulas"68 - is the example given by Bauer of the copular sentence of Ko Ihoa which is given to mean in English that "Jehova exists". ${ }^{69}$ Likewise, although more inferentially, from the example "Ko Paoa kua koroheketia, e tokotoko ana" to be found in Williams and translated there as "Paoa has become an old man", ${ }^{70}$ it

67 Legrand, above, n 12 at 111 and 120.

68

Winifred Bauer Māori (Routledge, London, 1993) at 78

69 Ibid.

70 Williams, above n 57, at 153 under the entry for kua. 
would be to explicate the so-called ellipsis in Māori that so upset Maunsell ${ }^{71}$ that we would dare to expand, not only for the purposes of fulfilling the expectations of English grammar, but also to explicate subtle nuances of te Reo Māori meaning (in terms of the naming, initiating, focussing and other fertile functions of ko to be later identified in this paper) that may not otherwise break through the English translation barrier. ${ }^{72}$

Consequently, and with the unexpected result of moderating most of Maunsell's strictures on te Reo Māori, it is worth while unravelling some of the various English fractals of meaning possibly conveyed in variously different situational contexts by Williams' given example of "Ko Paoa kua koroheketia, e tokotoko ana". In terms of target translation, Williams does so colloquially simply as "Paoa has become an old man",73 but to give differing subtle emphases appropriate to differing situational contexts or by source rather than target translation, and thus more literally when explicating the ellipsis of predication that otherwise would as, for example, accord more emphasis to Paoa as the subject of the sentence, then either "It is Paoa who has become an old man", or, in some different situational context, "Here is [or Here's] Paoa who has become an old man"; or more referentially (indicatively) "As to Paoa, he's become an old man"; 74 or expressing oneself more reflectively "Speaking of Paoa, he's become an old man". Of course there are many more and better ways of expressing these alternative meanings - whether more emphatic or more indicative, or more referentially or more reflectively, in Māori as in English.

There can be no end to linguistic any more than to substantive legal debate. Nevertheless, demonstrated by each of the two above examples, it is in this sense, despite many other and often cognate functions for the particle ko, that we dare to claim the particulate present indicative function (since there is no verbal copula in its own right) for ko. It is this present indicative function (no less than the naming and other fertile functions of ko, that come into play when undertaking any such

71 R Maunsell A Grammar of the New Zealand Language (John Moore Auckland, 1842). In his Introduction Maunsell characterised te Reo Māori for its "remarkable brevity and abruptness as well as by the frequent occurrence of ellipses" and for being "defective in particles of illation, comparison, and copulation". These rather chiding remarks, made perhaps mistakenly from a solely English point of view and by the lack of any more informed comparative approach, have been softened by attributing to Maunsell an appreciation of the way by which te Reo Māori uses situational context (pragmatics rather than syntax) to determine relationships between ideas: see B Biggs "Humpty-Dumpty and the Treaty of Waitangi" in IH Kawharu (ed) Waitangi - Māori and Pākehā Perspectives of the Treaty of Waitangi (Oxford University Press, Auckland, 1989) 300 at 301. Biggs holds Maunsell to be "perhaps the best grammarian among the early missionaries".

72 This explication into several English fractals of the te Reo sentence "Ko Paoa kua koroheketia, e tokotoko $a n a^{\prime \prime}$ is especially pertinent to relieving any source-translational feeling that, say, because the Preamble to the Treaty contains the verb constituent kua wakaaro, it is thus completely improbable that the same sentence would begin with a present indicative, and, what is more, one that is followed by a proper name.

73 Williams, above n 57, at 153.

74 Ibid. 
essentially comparative exercise as back-translating the Māori text of the Treaty of Waitangi into English.

What, then, would it mean for any attempt to translate the Treaty, whether from English to Māori at the time of the Treaty's drafting, ${ }^{75}$ or for the purposes of any back-translation from Māori to English, ${ }^{76}$ with the intention of securing as literal a translation as possible $?^{77}$ Whether from English to Māori, or from Māori back to English, the process of any professedly literal translation is still essentially a comparative endeavour, with few, if any absolutes, and sometimes no counterparts. Ko, being the very first word in the Māori text of the Treaty, poses this problem most acutely for any attempt at literal translation. ${ }^{78}$

What is meant by designating the linguistic particle Ko, to be found in Ko Wikitoria, the opening words in the Māori version of Te Tiriti o Waitangi, as self-referentially indicated by the present part of this paper in its being an accustomed exercise of the particulate present indicative used throughout te Reo Māori? There is no short answer to this question, since a grammatical function of the particle ko for expressing the present indicative mood in te Reo Māori has so far only been touched on, but never thoroughly analysed, far less identified, or recognised. Nevertheless, for almost every linguistic, logical, and legal operation concerning te Reo, the present indicative verbal operation of $k o$ can be said to be of significance for issues of categorisation,

75 Although translated from English to Māori for the purposes of drafting and presenting the Treaty, the English version of the Treaty, holding to its own level of literality, cannot be imposed on the Māori version without pre-empting the meaning literally held by the Māori version. The whole point of any backtranslation is to explore, discover, and critique the differences of communicative meaning arising out of the translation process as demonstrated by differences in the respective levels of literality.

76 Among the earliest of back-translations professing to be literal translations are those to be found in SMD Martin New Zealand in a series of letters (Simmonds \& Ward, London, 1845); EJ Wakefield Adventures in New Zealand (John Murray, London, 1845) at 459; and TE Young "Native Department" [1869] AJLC 7071. All three and other back-translations can be found in Phil Parkinson "Preserved in the Archives of the Colony': The English Drafts of the Treaty of Waitangi" (2004) 11 RJP/NZACL Cahier Special 92-97, where also at 97-101, can be found the now prevailing "[Literal] Translation of Māori Text" by IH Kawharu as intensively commented on and critiqued by both Kawharu and Parkinson. It was taken from IH Kawharu "Translation of Māori Text" in IH Kawharu (ed) Waitangi-Māori and Pākehā Perspectives of the Treaty of Waitangi (Oxford UP, Auckland, 1989) at 319-320.

77 As Parkinson (ibid, at 31) writes "The very idea of 'literal translation is suspect, as any translation involves some element of translation." See also Biggs, above n 71, at 303-305.

78 For example, what constituted a literal interpretation, as decided by construing Latin, literally word for word, as required for a grammar school education, made demands, right up to the middle of the 20th century, that no Latin word be left out or unaccounted for in the word-for-word English translation. Thus, even in professedly literal back-translations of the Treaty, Martin (see above n 76 substitutes now for Ko, and in the interests of English grammatical propriety and predication, Kawharu (see above n 71) translates Ko te as this is for the first, second, and third articles. 
predication, and propriety of expression, especially when used for the purposes of construing, interpreting, and translating at a cross-cultural level.

Not only is there no short answer to this question, but there may be also different and apparently conflicting answers given depending on whether the linguistic focus is either mainly morphological or else distinctively etymological. Likewise, as to what can be inferred from orthography, as demonstrated to a certainty by every living, changing language, is inferred only most cautiously from orthography, for what orthography is when applied to any recently written language, however responsibly, functions as an artefact. After all, not so long ago, continua scripta had all words running together; and although for Cyrillic in Russian and Roman in Māori, both written scripts in those languages are of relatively new employment, yet when compared with each other, the history of Cyrillic orthography is medieval in origin, whereas Māori is modern. It may be that Māori lacks the written documentation of centuries which Cyrillic provides for tracking word borrowings and word buildings - but interestingly enough, some of the same issues (for example the inferential or elliptic copulative for which ko serves the purpose of the present indicative filled by the dash in Russian) are still the same. ${ }^{79}$ So also, changes from prescriptive to descriptive grammars, for changes in standards of propriety for sentence construction, width of meaning, and equivocality of communication exact their own forcefulness, together with changing ideologies for linguistic study, analysis, comprehension, interpretation, as well as theories of source, literal, free, and target translation. Finally, in terms of any translation, what is taken to be a literal translation in its own

79 Besides the particle ko in Māori being quite rightly seen to have "no counterpart in English" (David Kārena-Holmes Māori Language: Understanding the Grammar (Kārena-Holmes, Dunedin, 1995) at 53-54) its immensely fertile function, which may be copulative, indicative, predicative, emphatic, specifying, initiating, focussing, co-ordinating, introductory, or interlocutory (see Winifred Bauer, above n 68, at 490); Ray Harlow A Māori Reference Grammar (Pearson, Auckland, 2001) at 82-83 and 193-196; and Patrick W Hōhepa A Profile Generative Grammar of Māori (Indiana University, Baltimore, 1967)) also makes the particle necessarily difficult to explain unless "understood simply through practice" (Kārena-Holmes, at 53). Both this fertility of particulate function in Māori as well as the failure of English to provide any obvious counterpart makes for difficulty in translation - a difficulty doubled for any attempt at literal translation, quadrupled for any back-translation, and exponentially increased for any attempt to secure precision in translating, say, the Treaty as a legal document. Nevertheless, however clumsy the attempt may be, even this clumsiness is worthwhile in providing a demonstration of the cross-cultural difficulty of providing any more exact linguistic, and in turn legal correlation. All the same, here's or there's serves not always in English to provide bluntly a purely locative function, nor always to give a spatial or temporal direction. "And there's Peter Walsh!" might be borrowed from literature (Virginia Woolf Mrs Dalloway (Vintage, London, 2004) at 159), by which, when relying on the introductory conjunctive, avoiding all emphasis on theirs, the resultant meaning, which could be enhanced by insertion of then before there's, becomes reminiscently commemorative instead of exhilaratingly locative. In the same way as ko serves many fertile functions in Māori, here's or there's serves the copulative or indicative, as well as introductory or interlocutory as well as for possibly salutatory purposes in English. As much as Kārena-Holmes situational linguistics (by way of "understanding simply through practice") operates through tone, intonation, and emphasis to determine the meaning in speech, the narrative context or literary genre may provide the same markers for the written text. 
time or for one of the languages, may no longer, or for the other language be seen to be so when the perceived relationship between both languages have moved.

Ko, as in Ko Wikitoria, the opening words of Te Tiriti o Waitangi, must surely be of more matter for being one of the commonest particles employed in te Reo Māori at every level of discourse, than to be dismissed as a throat-clearing particle "of no particular meaning" to which ko has been linguistically relegated in modern Māori. ${ }^{80}$ Among the understandably few attempts at a literal translation into English of the Māori version of Te Tiriti, Edward Jerningham Wakefield's back-translation of the Māori text, "Here's Victoria" for "Ko Wikitoria", ${ }^{81}$ provides a revelatory clue to those processes of predication and indication (both logical and linguistic) conveyed by this apparently meaningless particle.

Linguistics, at the interface of logic and language, enquires into phenomena to which the neural pathways of accustomed usage have already habituated the language user. If ko is both hiddenly predicative and indicative in its accustomed linguistic function, however, then revealing the very ordinary function of ko in expressing the present indicative (given an otherwise very minimalist expression of the present indicative in both Russian and Māori languages), ${ }^{82}$ opens up potentially fertile fields for linguistic exploration in Māori. Linguistic structuring and developmental restructuring, with formal differences (accentuated by orthography) made between long drawn vowels and short vowels, can so easily mask the same sources of conceptual origin. ${ }^{83}$

80 PM Ryan The Revised Dictionary of Modern Māori (Heinemann, Auckland, 1983) at 19.

81 Wakefield, above n 76, at 459. In Phil Parkinson, above n 76, Parkinson comments thus on the "Here's Victoria" translation: "Although Wakefield expresses himself oddly, he means to say that the 'Here's Victoria' text is an exact and literal translation of the Māori printed text - which was indeed printed, published officially in November 1844, with the English printed text." Earlier in Parkinson, above n 76, at 50, Parkinson describes Wakefield's translation as "clumsy" as "it is too literal", but this reason, as well as being Wakefield's intention to be strictly literal in his translation, is particularly revealing as to what is to be understood by the use of ko as an instance of the present indicative. Parkinson describes Wakefield's tone as being partisan, but Parkinson's conclusion, for being a legal and constitutional one, is no less partisan, for Wakefield writing that "Nothing could be more ridiculous than to see the arrangements for the cession of New Zealand, from the mythical 'Confederation of Māori Tribes' to Queen Victoria, as some kind of basic law or constitutional framework with enduring effect." Nevertheless, it cannot be denied that the Treaty has "endured" thus far, and with the "effect" of providing "some kind of basic law or constitutional framework".

82 Russian and Māori are not the only languages to provoke problems with the absence of present indicative or correspondingly assumed predicative verbs. The unnamed translator into English from the Latin of the Meditations of Marcus Aurelius (Collins, London \& Glasgow, undated) at 83, writes "There is no verb in this section connected with the word "from", nor in the following sections of this book [Book I]; and it is not quite certain what verb should be supplied."

83 The conceptual correlation by which hand-written words on a page can be ascribed to some already-known tuhiatuhia or sewing is plainly obvious; but pukapuka, when borrowed from existing Māori to mean a book, is no less fascinating for being much less obvious. Although allowing for a book or paper to be construed as pukapuka (which already in Māori exists for rangiora or Brachyglottis repanda), or else, according to 
Ko, as in Ko Wikitoria, the opening words of Te Tiriti o Waitangi, must surely be more than the particle "of no particular meaning". ${ }^{84}$ If only one could recover, not only the lost nuances of etymological meaning that distinguish between ko and kō, throughout the fertile field of Māori word-building, ${ }^{85}$ but also the common semantic origin that both ko and kō each must surely have in their still sharing the same familial concept of making a point, giving direction, and indicating a location. The hitherto overlooked verbal function of ko, ${ }^{86}$ a function never even considered far less co-ordinated with the function of other verbal particles such as ka, ma, i, e, na, and their built-up cognates, is both understandable and excusable without any but using Māori as its own singlelanguaged resource, and thus, for reasons shortly to follow, a source of perplexity only outside the context of comparative linguistics; but to dismiss the very first word of the Treaty for having "no particular meaning" contravenes every principle of literary translation and legal interpretation besides being also a hugely bad omen for interpreting and translating the rest of the text of the Treaty.

Williams (above $\mathrm{n}$ 57, at 306) is derived from some "similarity of sound, partly with the underlying idea of a flat surface", a deeper connotation in common possibly exists. When considered comparatively and conceptually from a book's bi-lobed opening and shutting, and from the rustling sound of its leaves, and as if a book were alive and breathing (no less than the reader used breath to utter the book's words) then pukapuka for book can also be construed as equivalent to the already existing Māori word, pukapuka, for lungs. Common semantic origins can often only be traced conceptually. In Russian, the words for bow (the weapon) and leek (the vegetable) are apparent analogues and not homologues (although, more superficially and morphologically, both homonyms). If one considers how leek seedlings develop, however, their stems are bowed backwards as they break midway through the surface of the soil. The homonyms emerge from the same conceptually common ground. Conceptual word-building and conceptual word-borrowing are no less, and indeed are far more important (and this for legal transplants, too) than formalistic and mechanistic categorisations (and this even more so for te Reo Māori when one considers the highly poetic, rhetorical and mythic qualities of Māori culture)..

84 Ryan, above n 80, at 19. Compare the very much fuller and more fertile account of $k o$ given by Williams (above $\mathrm{n} 57$ at 121) here interpolated

1. a particle [no less] used before proper names [ie Victoria, no less] ... to give emphasis [Here is Victoria, no less] and hence frequently to denote a predicate... [as where ko functions in the Treaty as the present predicative of Victoria, no less]

2. To direct attention to the subject [an indicative, as all indicatives indicate by way by way of pointing out] about which something is to be said [as said, no less, in predicating of Victoria what is to be done by her in the Treaty].

85 Over 30 pages of Williams (above n 57, at 120-153) are taken up with ko-prefixed words. Despite the systemic divisions, it cannot be overlooked that both aggregative and isolationist language systems evince trends running often counter to their systemic character

86 See the Preface: "The neglect of native idiom and grammatical form is a symptom of a far more alarming character [than barbarous transliteration]". Indeed, the barbarity of much transliteration may be attributed to what is heard by Māori, whether accurately or inaccurately, of mispronounced English speech. 
In the first place, it is wise to consider how width of meaning may so easily be mistaken for lack of meaning. Te Reo Māori may be notorious for its width of meaning in prose, but celebrated for its same width of meaning in poetry. Trickiness, if not treacherousness, was once acclaimed as a tribal virtue, and the same trickiness is bound to be manifest in the linguistic upbringing giving rise to that worldview. The linguistic wealth by which a Māori word of many closely related or even distinctively different meanings and functions - mana, rangatiratanga, noa, tapa, tapu - may all too easily be dismissed for meaninglessness rather than encourage the linguistic analysis required to engage in and master each word's both poetic if sometimes treacherous width of meaning.

In the second place, in so far as the answer to the attributed meaninglessness of ko lies in the context of comparative linguistics, the Russian language can be used to highlight the answer. Apart from the proto-european indulgence of the copulative est' as found for existential emphasis in "Bog est' lyubov" ("God is love"), the Russian like the Māori language finds no need (apart from the fractal expression of various degrees of emphasis) ${ }^{87}$ to indulge explicitly, as English does, in the present indicative. Underlying this shrugging aside of any use of the explicit indicative is the linguistic philosophy upheld by both Māori and Russian worldviews that <if there is something then that something is> and so such something may be the subject of any predication without any existential need by way of copula to rely more expressly on the present indicative of the verb to be. Neither Māori nor Russian worldviews have been as exposed as other worldviews, have been been more obviously exposed to Aristotelian predication and the Traditional Formal Logic of the Middle Ages; but just as Māori has allowed the particle ko to serve the same existential function as part of that particle's wider operations, so also Russian, in its accustomed absence of any more explicitly present indicative, has developed the attributive form of adjectives.

For all words such as ko that serve as indicators, from here (is), and there (is), to now (is), then (was), and so beyond to then (will) there are numerous permutations or fractals by which to communicate different shades of meaning. From the legal point of view, however, apart from the inherently present indicative verbal function of the particle ko, the wider meaning of the same particle in the Treaty, both in terms of pointing out (or, as we shall see, more in terms of digging in) and giving rhetorical emphasis to what is next to be predicated of Wikitoria means not much more, in terms of both source and target translation, by which the Common Lawyer would already be accustomed to understand of the expressions "In re ..." or "In the matter of ....". Neither of these expressions do injustice to the Māori language, neither by way of source or target translation, as does the purportedly literal but, for the sake of literality rather than reality, the somewhat belittling translation (much more belittling to English than to Māori) of "Here's Victoria".

In so far as any retrospective analysis of a recently written language is still conceptually available for Māori, linguists must someday hope to account for such word-relationships as "ko"

87 In Māori most usually before proper names and the definite article, in Russian by way of a more insistent predication. 
("to dig") "koeko" ("to sharpen to a point"), "kō" ("a digging stick"), "kōanga" ("springtime"), "koanga" ("happiness"), and "koha" ("a gift"). The world awaits a semantic analysis for the wealth of words in Aotearoa prefixed by either ko or kō in Māori word-building. The consonantal $k$ sound (to which $n g$ either shifts, or else has been long retained, in southern speech) is probably one of the most fundamental sounds summed up in the names for both the kiwi (surely kiwī if not kīwī) and the kō-ka-ko of this country; but the loss of the aspirated wh in favour of the more brutal $f$ barely makes up for the ongoing dynamics by which, when $l$ eventually supplants $r$, the Samoan fale supersedes the more traditional Māori whare. Nevertheless, Aotearoa awaits with bated breath the first Māori dictionary based on the word-building principles of Slavic linguistics.

So, too, word-building is no less fertile and ongoing in Māori than it is in Russian. Russian, however, is a rigorously inflective language, whereas Māori (together with English more and more) is the reverse. Particles and articles (much to the discomfiture of second-language students) carry subtle nuances of meaning that are lost to inflective-speaking peoples. Ko and kō frequently operate as particulate fractals of varying emphasis - but that need not, nor should relegate their function to "one of no particular meaning".

The pivotal point of the cultural polarisation between Māori and Pākehā arises unavoidably out of the Treaty. The first two words of Te Tiriti o Waitangi - Ko Wikitoria - provide a paradigm for all the troubles of two different tongues coming together, and this although both tongues did so professedly with one accord. These two words Ko Wikitoria point out, indicate, and now stand for the modern reversal of many still much misunderstood Pākehā-Māori roles. Not only would many of the Māori-English words used in the Treaty be no longer used today, but so also many of the classical meanings of the words used in the Treaty have now moved on. They can only be argued over, as they are still argued over by both Māori and Pākehā in the present, as misleading anachronisms.

Sovereignty, even to the Pākehā, has almost entirely lost its meaning at every level of government - legislative, judicial, commercial, and administrative - in today's transnational, and even supranational world. Vis-à-vis only Māori and Pākehā does any argument remain for each to argue in claiming their country's appropriate balance of power; but by now both parties are debating kawanatanga not sovereignty or tinorangatiritanga. Multiculturalism has only served to increase rather than decrease whatever there once was of a much more restricted bicultural misapprehension.

Were one to deal with the last-mentioned word first, in accordance with the long-lost oral convention of a now literate legal profession, Wikitoria is simply "te Kuini o Ingarani" - the Queen of England - although England becomes United Kingdom in the English text in deference to the Celtic faction. Wikitoria te Kuini o Ingarani does not cause much of a problem. All the same Te Tiriti, as the document itself recites, was still executed "at Victoria" (Busby's British Residence) rather than simply at Waitangi. Mr Busby's Station at Waitangi, named Victoria, and known to the natives as Wikitoria, so appears in the attestation clause for the Chiefs of the Confederation as "being assembled in Congress at Victoria, in Waitangi". New Zealanders now prefer to overlook 
Victoria as the name of the place at which Te Tiriti was signed as much as they overlook it as the name of the person on whose behalf it was signed. So Wikitoria does not raise any obvious problems. On the contrary, it is the Māori particle ko which really perplexes the Pākehā. It is now often only the little word ko which prevents the Pākehā from forgetting all the promises made by Queen Victoria - Ko Wikitoria - to Māori on his behalf.

Wakefield's first attempt at literal translation in 1845 of the Māori version of the Treaty, therefore, was incorporated into TL Buick's ${ }^{88}$ standard text on the Treaty, the words "Ko Wikitoria" of the Māori text have been back-translated as "Here's Victoria". This literal translation has had the nasty effect in English of appearing to demean the Māori text. An even more unfortunate result is to demean the Māori language - as if it were beyond Te Reo Mãori to cope with conveyancing recitals. A more spirited account might still indeed be Here's to Victoria, just as all nineteenth century public gatherings began by singing, and a lot of legislation ended by proclaiming God Save the Queen were our worldview still as then.

"Ko Wikitoria" - "Here's to Victoria", then, but which comes first, words or thought? Here is a moot point. We can look at whatever words are used within the four corners of any document, but we still need to know the mindset from which the words spring forth onto the written page in order to find out what they mean for the written page.

Again, we may ask, what comes first in deciding the law - language or logic? The first word - if it really is a word and not merely a particle of thought - of the Treaty is ko. This, although serving a multiplicity of functions, is the specifying particle. Ko substitutes for the index finger. It has a point to make a point, an indexing function, a marker as some commentators call it, which just is not provided by the English language. And so it causes problems for the literal translation of the Māori text of Te Tiriti. "Here's Victoria" demonstrates a shortcoming of the English not the Māori language.

Te Reo Māori provides a great wealth of what is, when compared with English, a peculiarly particulate language ${ }^{89}$ This means that te kaha o te Reo Māori - the strength of the Māori language

88 "Here's Victoria" for "Ko Wikitoria" passed into popular parlance from the earliest editions of T Lindsey Buick The Treaty of Waitangi or How New Zealand Became a British Colony (S W Mackay, Wellington, 1914) at 102-103, being transcribed (although ostensibly from other sources) actually from Edward Jerningham Wakefield's professedly literal, but also possibly partisan translation in Adventures in New Zealand, above n 76.

89 Needless to say, peculiarly is used in the classical sense (from Latin peculiaris, meaning any private or exclusive property) of that autonomously unique and thus peculiarly identifiable character that helps enhance and explain the indigenousness of Māori culture; just as "particulate language" is used generically, in so far as tracking through the Shorter Oxford Dictionary for the years 1959-2007, denotes any particle in the grammatical sense can be understood to be a minor part of speech, especially one that is short and indeclinable, a relation-word (1959 ed) or function (2007 ed); also a prefix or suffix having a distinct meaning. As for the term particulate, as derived from particle, this has been in scientific use since 1874, and is now according to the Shorter Oxford Dictionary (2007 edition) to be attributed with more common usage. 
- lies in lots of little words. E, te, a, nga, o, ko, no, na, mo, me, he, hei, hea, tehea, pehea, ana, aha, ano, and so on, occur over and over again. Pākehā, with their own expletives or filling-in words, tend to mistake these particles for expletive or filling in words. On the contrary some, such as te, he, and nga, tell the number of nouns. One, the particle ko, besides many other just as important functions, has a most important pointing out, or indexing, function. Some particles, such as e and a, distinguish personal pronouns and proper names. Some, such as o and a, distinguish between different kinds of possession. The kinds of verbs, as well as their moods and voices, are likewise expressed by such simple particles as kei te, i te, kua, kia, e, and so on. To these particles we have just added our discovery of the particulate present indicative - however elliptically or subliminally expressed. The power of particles means that te Reo Māori possesses a simple, straight-forward, although subtly-nuanced strength, in those areas of many Pākehā languages that are complicated by declensions and conjugations.

The strength of simplicity that arises from te Reo Māori being a particulate language ${ }^{90}$ poses problems for the Pākehā. To concentrate on the little word ko, as we do so now, is not just because it is the first word o Te Tiriti, nor even just because it is a paradigm of the problems posed for Pākehā by the particulate nature of te Reo Māori. The fact is rather that a revolution has taken place recently in the language of the law in New Zealand. Standing Orders 104 and 352 of the House of Representatives providing for the use of te Reo Māori in parliament are long established. Sections 3 and 4 of the Māori Language Act 1987 provide for te Reo Māori as court communication. This legislatively establishes te Reo Māori as one of our now three official, and thus, presumably legal languages - English, Māori, and Sign language - in Aotearoa.

Even just for ko itself, as in any short text such as the Treaty. This is much more so elsewhere as in Te Paipera Tapu:

Ko te pukapuka o te whakapapa o Ihu Karaiti, tama a Rawiri, tama a Aperahama. Na ko ta Aperahama ko Ihaka; ta Ihaka ko Hakopa; ta Hakopa ko Hura ... Ta Hura raua ko Tamara ko Parete rua ko Hara; ta Parete ko Heteromo; ta Heteromo ko Arame ... ko IHU: Ko te Rongopai ki te Ritenga a Matiu, Ko te Kawenata Hou a tatou Ariki a te Kaiwhakaora a Ihu Karaiti.

Indeed, one only has to count up and consider the function of the fifty or so words that Biggs (see B Biggs, "The Māori Language Past and Present" in E Schwimmer (ed) The Māori People in the 1960s: A Symposium (B\&J Paul, Auckland, 1970) 65 at 69) considers to be particles, to evaluate their usage as belonging to the haecceitas of te Reo Māori. Since the verb form does not itself change in Māori, for which particles exercise the mood-changing verbal function, te Reo Māori is thus bound to be particulate in its essential function. The Māori verb, and in turn, the Māori language, could not function as they function, without particles. It is a functionally particulate language, in the correlative way that the Russian verb uses aspects to serve a similar linguistic function as an aspectual language.

90 The concept being considered here is one of linguistic sensitivity. An example would be the way in which, for verbs of action, te Reo Māori distinguishes between the means of motion, whether personal or vehicular, according to its control, much as Russian does the same between verbs for motion on foot and verbs for vehicular motion. 
Less than a generation ago, Latin and Roman Law was compulsory for lawyers in New Zealand. Educational values have a habit of turning turtle. Less than a generation hence, those who practise law here may need to know Māori as a main means of legal communication. It is already clear that we need to consider the particle ko more carefully and at even greater length than we already have - as with also the words Ko Wikitoria that begin Te Tiriti.

Literally speaking, a greater length given to ko makes of it a different word. Lengthening the vowel turns the abstract indexing function of ko into a digging stick - something used to poke into the mother earth of Pāpātūānuku. The problem for the Pākehā in understanding this is how to distinguish the figurative function of the linguistic index finger from the more demonstrative sound of the digging stick. Because the Pākehā perspective belongs to a written culture, the Pākehā wants to index differently the diverse sounds. Accordingly, he either doubles the vowel, koo, or uses a macron, kō, to denote the lengthened vowel. The educational advantage gained by the orthographic use of macrons as markers in Māori (akin to the more limited educational use of udaryeniye in Russian) no doubt has been carefully considered against the forcefulness of a morphological implant (akin to the legal implant) that can hide and distance if not outrightly extinguish still existing etymological derivations. This is likely to remain a controversial area shared if not also divided by both morphological and etymological arenas of linguistics.

Paradoxically, te Reo Māori becomes even more particulate when hyphenated for the convenience of Pākehā as was once written by A W Reed. Fortunately, the rather condescending convention of using italics for Māori words in Pākehā prose has now almost entirely disappeared. On the other hand, the contrary convention of overindulging in capital letters has so far taken its place as to endanger the development of Māori-Pākehā prose by returning its typography to the selfingratiating style of the seventeenth century. The way things are going it looks as if every third word will end up being capitalised. No one has yet suggested the use of the Slavonic stress (udaryeniye) in place of macrons, or the Samoan apostrophe to represent the glottal stop.

The trouble for te Reo Māori as a result of such debatable hieroglyphics is that it ends up with different written dialects of the same te Reo Māori. If the truth be known, there are probably more tribal dialects as a result of Pākehā writing down Polynesian languages than there ever were before the Pākehā came to Polynesia. Originally, whatever beauty lay in differentiating between Samoan fale and Māori whare may have been peculiar to the auditory canals of different Pākehā. Still, the indexing function of ko, once te Reo Māori is written down, not just figuratively points out, but literally digs in to plant out. There has never been any doubt since Te Tiriti began with Ko Wikitoria that the professed object of Te Tiriti, whether later dishonoured or as yet unfulfilled, was to effect a legal transplant of equal rights (nga tikanga katoa rite tahi ki ana mea ki nga tangata o Ingarani) secured by British sovereignty (ka tiakina e te Kuini o Ingarani nga tangata Māori katoa o Nu Tīrani). Although the 20th century historian may anachronistically reinterpret Te Tiriti in terms of today's power politics, the fact remains that the age old equation of sovereignty with responsibility lasted long after the death of Queen Victoria. 
New Zealand English, especially in its most free-willed of linguistic borrowings, evidences its own centripetal attraction for South Pacific loanwords. Partly explained by the missionary zeal for Māori education from 1814 onwards, later by the cultural idealism pervading the period of the British Residency under Busby since 1833, later still by the he iwi tahi tatou principle explicitly avowed by Governor Hobson under the Treaty of Waitangi in 1840, New Zealand English began to rethink itself in already 19th century terms of haka, hangi, kai, kapai, kōrero, kur1i, mana, Pākehā, pīkau, taihoa, waka, and whare. ${ }^{91}$ Rather differently, both in origin and motivation, this spontaneously free-willed extension of both word and thought would be bolstered by a loanword vocabulary increasingly conveyed in person by a continued South Pacific immigration that would reprise New Zealand's notably imperial aggrandizement of the South Pacific. Culturally insensitive, sometimes violent, and occasionally brutal, as could be New Zealand's early government of Samoa, or, as in 1889 when the New Zealand Government illegally threw Sunday Island (now renamed Raoul in the Kermedecs) open for land settlement under the noses of its already land-owning inhabitants, ${ }^{92}$ many already long-ensconced word borrowings, the most significant and fundamental of these being Māori and Pākehā, would mutate in meaning, while in place of the now dropped-out but mutually affirmative concept of Pākehā-Māori, ${ }^{93}$ a new concept of Palangi would enter with the potential for disruptive intrusion into thought and action. ${ }^{94}$

The emphasis for any language that is alive is bound to be always on the mutability of meaning, rather than on the dictionary-dead semiotics of the more apparently formulaic word. Thus, the semiotic taihoa, source-attributed to 19th century Māori for its inclusion in New Zealand English, when taken to mean "stop, wait, or hold up", may yet turn out to be no more than a corruption (with

91 This list, as substantiated by the appendix of the Oxford Dictionary of Foreign Words and Phrases (above $\mathrm{n}$ 66, at 507), is purposely restricted to 19th century source criteria for Standard English. However, for New Zealand English the list, including not only place-names but also botanical and zoological names, would of course extend to everyday words such as pa, pataka, marae, moko, tangi, ariki, rangatira, and so on to incorporate hundreds of thousands of transplanted loanwords, knowingly or unknowingly, into New Zealand English.

92 See Elsie K Morton Crusoes of Sunday Island (AH \& AW Reed, Wellington, 1964).

93 For example the works written under the soubriquet of a Pākehā-Māori by Frederick Edward Maning on Old New Zealand; for example Frederick Edward Maning History of the war in the North of New Zealand against the chief Heke in the year 1845/ told by an old chief of the Ngapuhi tribe; faithfully translated by a "Pākehā Māori" (Geo T Chapman, Auckland, 1862); Frederick Edward Maning Old New Zealand: being incidents of native customs and character in the old times, by a Pākehā Māori (Smith, Elder and Co, London, 1863).

94 Nevertheless, in Williams, above n 57:

... the fact must be recognised that the occurrence of these words cannot be regarded as a symptom of linguistic decay. On the contrary the power of enriching the language by the assimilation of exotic material is evidence of continued vitality. It is only when a language is dead that its vocabulary is absolutely fixed. 
a terminally echoed, elongated, and thus more open-mouthed a) of the English nautical command to "Tie-ho!"

Is it too far-fetched to conjecture this nautical command for its being heard, and increasingly uttered with the same meaning by the Māori whenever a sailing ship, canoe, or even just a ship's boat, were tied to some tree-trunk, or eventually to some wharf once wharves were built ashore? If not, then in being originally an English expression so effectively transplanted into Māori as to be mistaken subsequently for a Māori expression transplanted into English, we have an instance, probably not all that too etymologically uncommon, of squaring the linguistic circle.

Such purely phonetic exchanges are not so uncommon or so far-fetched as they may later appear when once written, and by their then written appearance, ascribed to different origins. Consider even for the transliterated transplants of the proper names we are so sure about in their being transplanted (originally from Hebrew) but, as may appear to Pākehā, originally from English - "Hone" for "John", "Hēmi" for "James", "Hōhepa" for "Joseph" - these by now are so distinctively Māori as to be fit to be re-transplanted back (as they are) into English.

Likewise conjecturally, does kara, for the flag cut down at Kororāreka by Heke and others, testify to a concept for naval and military colour(s) emerging much earlier from the source-heard mispronunciation of parade-ground and barracks-room English? Kala, when transplanted with a logically transmuted " $r$ " for the by now defunct Hawaikian "l", is not far remote from such paradeground mispronunciation of colours. Such un-memorialised exchanges soon drop from sight leaving behind only conceptual tracks masquerading as poetic and not even mythic conjectures. Nevertheless, this new word kara might evidence the gain to Māori people of a generic concept ${ }^{95}$ that had not until then abstracted itself from the severally independent and specific whero, ma, and puru representing ko nga kara.

\section{THE TIME-BINDING FUNCTIONS OF LAW AND LANGUAGE}

Notwithstanding the centripetal attraction of New Zealand English towards and into te Reo Māori ("poaka" for "pork", "pāreti" for "porridge", "hoiho" for "horse", "hepi" for "sheep") versus the very few centrifugally ejected linguistic exports from the South Pacific ("haka" for "dance", "whānau" for "family", "tapu" for "forbidden", "taonga" for "treasure"), the centripetally attracted imbalance of trade, at least at its height, distorts and destroys the linguistic and cultural identity of those whom it often seeks whole-heartedly to benefit yet ultimately victimises. Cargo-cults can be ignorantly, yet still mischievously created, being proclaimed as much pro bono publico by today's free-trading treaties as by attempts to extend civilisation on the basis of democracy and free elections. They do so not only by opening markets for the supply of physically tangible, material assets, but also by giving rise to a hunger for the new words and ideas on which the prevailing 
technologies and material resources rely for their manufacture and function. It is difficult to decide which is more adverse to the maintenance and preservation of any, indigenous cultures - the wealth of new technologies, tangible assets, and material advantages, or the resulting spin of new words and the novelty of unheard-of and frequently misunderstood ideas. The former Soviet Union, no less than the Old and New Russias, has been no more freed from the risk of cargo-cult contamination than have been the islands of the South Pacific.

Since, on the Whorfian hypothesis one's worldview is the result of one's linguistic upbringing, any change to one's linguistic upbringing will affect one's worldview, and since the law relies on language for changing worldviews, any change to language will critically affect the law. Linguistic explosion (as of English or any other lingua franca) necessarily entails linguistic implosion (as of Māori and Gaelic) no less than Greek as a lingua franca displaced Hebrew, and, until recently in the academies, Latin lorded over English even in the sciences. This not entirely free-willed arena of linguistic appropriation and expropriation, by reason of first notably that it exists, secondly that it engages at a conceptual rather than merely semiotic level even although its movement may be mostly (or for a time) one way, and thirdly that legislative enforcement, rather than effecting reverse linguistic discrimination, is bound to accord with the linguistic flow of travel, is jurisprudentially essential for even the barest minimum of legislative deployment.

Whether a language is stable enough in its structured form and function to hold to its own communicative values is of deep concern to the lawyer in his concern for the clarity, certainty, consistency, and continuity of the law.

This most metaphysical concern for these criteria particularly affects the legislator or lawmaker and the draftsman of documents (both involved with time-binding activities) ${ }^{96}$ where any statute or other document is designed to transcend time, carrying its clear, certain, and constant message from the period of the document's making, through the present instant the document's confirmed and completed execution, to what may be for the document the lengthiest of interpretation and enforcement operations.

Language functions with the same postulated constancy as once the speed of light was taken by Einstein to operate for the theory of relativity. Prescriptive grammars and etymological dictionaries for language together with traditional logics of predication, categorisation, and definition for concepts, provide at least a debatable basis for linguistic stability instead of today's denotative dictionaries and descriptive grammars based on usage by which anything goes.

96 Time-binding, as a concept in the field of general semantics, whose basic premise, according to Alfred Korzybski is that "language 'enslaves' us by conditioning our brains to perceive a false reality" (A Okrent In the Land of Invented Languages (Spiegel \& Grau, New York, 2009) at 200) owes its origins to the writings of Korzybski; and, in particular, to A Korzybskii Science and Sanity, an Introduction to Non-Aristotelian Systems and General Semantics (5th ed, Institute of General Semantics, New York, 1994). 
The result of losing out on any prescriptively measurable standard of language for the law is compounded for both language and logic by today's dictionaries based on definition by popular usage. And the resulting loss of linguistic authority, on which the authority of the law is largely based, erodes legal authority. If language lacks its own institutional clarity, constancy, and certainty then the law, which in itself is a time-binding mechanism by which to constrain human conduct, likewise falls into disrepute through lack of established authority.

Without the benefit of any more cosmological constant as that demanded in modern physics to make up for inconstancy in the speed of light then likewise for the law when founded on the increasing inconstancy of language, the result is increasingly to reverse the equation by substituting the ever changing linguistic medium for the continuingly presumed constant legal message.

Where the theory of constant language on which the law relies has thus, moved mightily under the feet of the law then, as famously formulated by McLuhan and Fiore, ${ }^{97}$ "the medium is the message", and is so absolutely.

The formula for this reversal of values may be explained by the forcefulness of the dynamic over the static, especially in any context of values where change is equated with, and presumed if not assumed to be progress. Yet, in all this loss of constancy, and ensuing loss of certainty, what most fascinates any serious enquirer into the cause and consequence of this loss of legal authority is that the law takes the brunt of all the blame for the reversal of means and ends by which "the [linguistic] medium [becomes] the [legal] message". The accomplished end of the law is thwarted by the failed instrumental how of the law's linguistic means.

From transmission to reception, it is the recipient alone now who is invested with every right to determine what he makes of every utterance. Yet, the resulting mismatch or faulty equation operates to the cost of legal certainty, consistency, and continuity. The resulting difficulties of drafting, interpretation, and enforcement, thus, take their toll on the authority of law.

Linguists who concentrate on the systemic character of a language - for example its morphological integrity and consistent rules of grammar - in order to sustain and preserve its indigenous character, may also worry that for the lack of being creatively innovative. Such languages (like static legal systems or closed societies) are actually in decline and breaking down. Thus, to give a clichéd yet historic example, Golden Latin gave way to Silver Latin then corrupted itself off into French, Romanian, Italian, and other Romance Languages, until, for the lingua franca of scholastic purposes it finally devolved into the base metal of Medieval Latin.

97 A pun on Mass Age (for Massage) and Mess Age (for Message): Marshall McLuhan and Quentin Fiore The Medium is the Massage: An Inventory of Effects (Penguin Books, United Kingdom, 1967); see also Marshall McLuhan Understanding Media: The Extensions of Man (McGraw Hill, New York, 1964). 
Both the dynamic processes of linguistic expansion and malleability, and on the other hand, the custodial and often static means of linguistic preservation, are often likely to be in conflict. Thus, the paradox of linguistic universality, by which some language becomes more widely used and understood, poses problems of linguistic value akin to the biological origin and development of species, dependent as they are as often on isolation as on accessibility for their separately systemic and characteristically unique development. As for legal transplants into any legal system so also for extending any language system, the price for both legal and linguistic progress is that of deeply intensive linguistic analysis.

Such experimental and possibly innovative languages readily give rise to new ways of saying things. It may be that their concepts are fluid, less than categorical, as might be the case for both Māori and Russian, neither of which languages have been pinned down to any strictly Aristotelian process of categorisation that would, for its looseness in logic, frown down on such things as ellipsis and analogical reasoning. Instead, categorically-imbued languages may freely borrow from other categorically-imbued languages for their process of cross-fertilisation. On the other hand, they may develop and create new ways of saying things entirely within themselves. This self-contained creative development is akin to the process of parthenogenesis or self-reproduction in biology. Just as isolation, with all its attendant risks, may be conducive to the origin of biological species, so isolated communication, with all its attendant risks, may be conducive, in the development of any language, to its coordinated and systematic exposition.

\section{WHAT SLAVIC LINGUISTICS REVEAL FOR LEGAL TRANSPLANTS IN THE SOUTH PACIFIC}

In sharing the South Pacific with what we presume to be only ourselves, we are often too closely confined to analyse our own communicative issues with each other, far less to pinpoint or recall from where the concepts of "transparency" (glasnost) or "restructuring" (perestroika) so recently emigrated from Slavic sources into our own Pacific culture and legal system. Ephemeral loanwords may nevertheless leave lasting impressions no less than those of indelibly dead or dying legal transplants. Neither Māori nor English have any cognisance so markedly defined, explicitly recognised, and generally accepted, as do the Russians in having both their own word and clearly defined concept for "word-building" (slovoobrazovaniye). The English language barely allows a hyphenated approximation to any such completely integrated concept of word-building as have the Slavs.

It should also be noticed that until any borrowed foreign word is fully accepted and integrated into the Russian language, it keeps its alien status until being engaged into the inflective word system. Modern Russian maintains no less than 300 of such indeclinable foreign loan-words. Thus, even the noun plyash, long borrowed from the French for the concept of the foreshore or the beach, still barely, or if so only recently, declines through cases. The Society of Lovers of the Russian Word, founded by Aleksandr Shishkov (1754-1841) in 1811, still exerts its cautionary influence, as 
the author has heard argued by academic linguists in the late twentieth century; and the same nationalistic caution if not suspicion of Western legal transplants. ${ }^{98}$

Not having our own word in English for word-building as do the Russians, we rely only on what we have of innate creative instinct. Self-analysis is so uncomfortably close that we prefer to analyse instead of ourselves the other fellow. Nevertheless, as the first New Zealander to attend the (then Lenin) State University of Belarus in Minsk in 1991, the author tried to persuade Russian linguists to build from novo-zeland-yetz the word novozyelandyetz (for New Zealander). His suggested neologism or new word was closely modelled on shotlandyetz and amerikanyetz. No indigenous linguist was even mildly amused. On the contrary, the prevailing response conveyed was rather one of linguistic outrage. Much to the dismay of his South Pacific heritage, the speaker was told quite categorically (admittedly under the old Soviet regime) that such novelties were not permissible. Any further debate would have branded him (at the very least) a nyekulturnyii or rudely uncultured person.

As for the built-up word nye-kultur-nyii, word-building is a continual process of both semiotic as well as of conceptual hybridisation. The etymological viability is measured in terms of strength, adaptability, and mutability of both scion and rootstock. Conceptually, that puts word-building, whether for Russian or any other language far ahead of grammar both in evaluating the linguistic strength as well as in the teaching of the language. Slovoobrasovaniye or word-building serves as the traction engine for the Russian language, whereas grammar, as for any language, is merely the guard's van.

According to the old adage that everything flows towards Moscow, the author discovered in 1995, while at the Lomonosov State University of Moscow (known by its acronym, MGU), that the Russian language had learned to accommodate novozyelandyetz, and this no more than four years after the author's earlier experiment in Minsk. With the perseverance of the far-travelling linguist Lomonosov, who literally walked across Russia to study at MGU and now gives his name (in place of Lenin) to this Slavic equivalent for Russia of Oxbridge in one, the word novozyelandyetz had apparently burrowed all the way underground from Belarus. The Pripet Marshes apparently posed no problem - nyet problyema - to any novozyelandyetz or South Pacific pioneering neologism. This new word had independently burrowed its way into the accepted russkii yazik (the Russian language) of Moscow University's Russian Language Institute. Back to MGU in 1996, the author again confirmed that novozyelandyetz had taken an even firmer hold on the Russian language. Not only novozyelandyetz in the singular but also novozelantzii in the plural had become completely acceptable to the new Russian Federation.

98 "The process of westernization of Russian economic, social and intellectual life, which was deliberately and energetically set in train by Peter I, brought with it a whole mass of foreign loan-words": Auty, see above $n$ 33 , at 31 . 
Everything once flowed towards Moscow as much as the English language still seems to suck in all other languages into a black hole. Without being that sort of space scientist, the author (although with tongue firmly in cheek) still takes full credit for having introduced the word for "New Zealander" into the Russian language. What is more important, however, is to fulfil the correlative responsibility to the Russian language for effecting the New Zealand connection. As for any legal transplant, so also for any linguistic borrowing, will the New Zealand connection have been made completely in accordance with the rules for Russian word formation.

The Russian language is strongly accepting of borrowings from other languages. This process may begin by being purely imitative, but words such as democracy, party, and bourgeoisie soon resonate with their own Slavonic connotation. So now even the word novozyelandyetz will resonate at least in Moscow if not in Minsk. Indeed, even just by the absence of an initial capital letter, never mind the Cyrillic rather than Roman alphabet, this concept of novozyelandyetz is now as much a Russian as it is a New Zealand concept. But beware, the magnetic forcefulness with which the Russian language captures these new concepts is more than sufficient to absorb, digest and convert them into its own cultural idioms.

Of course sometimes the conflict for supremacy between two such very fertile languages as English and Russian can be so intense as to make a great writer such as Nabokov unable to continue writing in both. The same sort of bilingualism can affect whole countries at a national level. For similar sorts of reasons, Russian linguists worry that excessive borrowing, especially now from the English language, dilutes and distorts the structure of the Russian language. After a lifetime's study of both languages, however, the author has no such worry for the survival of Russian. With the closure of so many foreign-language schools in English-speaking countries, and the opening of so many English-teaching schools in so many foreign countries, one can now have far more uneasiness as to the survival of English.

It is the universality of English that in turn makes this lingua franca vulnerable, such is burden of its celebrity status, for being a cosmological black hole into which is drawn every other language, together with every speaker and writer of that other language in his or her own efforts to come to grips with English as today's lingua franca. The same can happen to legal transplants of what we most value as being concepts of freedom, human rights, and democracy, and the legislative means by which we would implement and enforce them. Their global recognition renders them vulnerable.

The same uneasiness pertains to the attempted exportation, of legal concepts such as the separation of powers or the rule of law. Just as any language, like any empire, can be brought down by over-extension, and this even more particularly in its own indigenous jurisdiction, so too the original concept of what is meant by Western democracy, by the Bill of Rights, by the separation of 
powers, or by the rule of law, may falter, fail to thrive, and eventually disappear from its own jurisdiction of origin, by being extended into climes that cannot as yet support its endeavour. ${ }^{99}$

Today's option in almost every field of endeavour, literary as well as scientific, is to chose, to read, write and speak the English instead of the Russian language. For the moment it may be more politically correct, and commercially viable, to employ the English language, but today's expediency could prove quite transient. Languages, like fashions, have their vogue. Once it was Koine or Mediterranean Greek, then in the Middle Ages Latin, which became the world's lingua franca. In any case all such statements, whether about law or language, are not only culturally, but also historically and geographically relative. Sir Henry Maine was able to upturn the whole world of law, and in particular the Common lawyer's role from that of being a legal custodian to being a social reformist, on the basis of no more than an assumption that "The most celebrated system of jurisprudence known to the world"100 was indeed that of Roman, and not say Hebraic, far less English law. He managed to do so simply because in this personal assumption he shared also the general assumption of his own culture and time.

Legal systems are not unlike languages in their passing in and out of vogue. As with linguistic enthusiasm, the same legal enthusiasm can move its allegiance from private to public law, from institutional to constitutional law, and from national to international, transnational, supranational, and global law. As old legal allegiances grow cold yet new ones remain unfulfilled, the once novel and exciting legal transplants from abroad calcify where they remain unabsorbed. Calcified legal transplants get in the way of further legal development. They begin to burden rather than to liberate and facilitate the legal system into which they have been so enthusiastically transplanted.

For many reasons of both law and history, and perhaps most of all on account of its protracted and often isolated development, the Russian language, like that of the Māori language, is far more resourcefully receptive than even the English language. The innate forcefulness of the Russian tongue certainly exerts a centripetal attraction for foreign words and concepts. By itself this could well disturb the integrity, dilute the forcefulness, and diminish the autonomy of the Russian language. And for words denoting such calcified concepts as seks (for sex), dzhaz for jazz, viski (for whiskey), bisnisman (for businessman) and pik for peak-hour traffic, this surely happens. More than the legally transplanted rule of law and separation of powers show signs of failing under the new Russian Constitution, one would pray for seks, dzhazz, and viski being only short-term loans.

Thanks to a number of critical factors, however, the Russian language retains a high level of linguistic absorption. The word bisnisman, by applying also to the Russian business woman,

99 For some of these risks in the former Soviet and new Russian Federation see Nigel J Jamieson, above n 49; Nigel J Jamieson and Alexander Trapeznik, above n 46; and Nigel J Jamieson "Text and Context in Russian Legislation with Specific Reference to the Russian Constitution" (2009) 15 NZACL Yearbook 11.

100 Henry Maine Ancient Law (John Murray, London, 1861) at 1. 
provides a good example of Slavic mutability It is always a moot point in English as to whether any policewoman is either more, or the same, or else something less of a policeman, or that any business woman is either more, or the same, or else something less of a businessman. The Russian bisnisman, which includes the business woman, poses no such gender problem.

Among the many critical factors that explain linguistic mutability, first attention is usually paid to the rigorously disciplined and logically constructed grammar of the Russian language. Sooner or later plyash (from the French) admits of na plyashe, and the far older borrowing of sluga (one of the few Celtic loanwords) achieves the status of a full declension. Languages that decline, preserve their own innate individuality and indigeneity. In turn, the successful implantation of a foreign word into Russian is signified by that word eventually having embraced the process of inflection.

Second-mention among factors ensuring mutability is usually made to the long established but as yet still dynamic process of slovoobrazovaniye or word-building in Russian. This order of importance - first grammar then word-building - should be reversed even for elementary teaching purposes. Learning Russian grammar without word-building is pure rote, as it can also be for teaching English as a second-language. Teaching languages grammatically rather than by immersion often defeats the teaching purpose by interposing an artificially academic intermediate language between the two real languages concerned. Word-building explains grammar, not the reverse. Deadly declensions and confusing conjugations are brought to life by an intimately conceptual knowledge of word-building. These tables of apparently dead data by way of declensions and conjugations then spring to life as fascinatingly creative phenomena.

The third critical factor accounting for the ability of the Russian language to hold its own against all comers is the deep and strongly integrated sense of its own Slavic heritage. Despite all present appearances, the Russian language remains both intimately innovative in its assimilation of foreign intrusions, and transcendently self-creative in its extension of them. The Russian language continues to serve as a logically complete, independent, and comprehensive cultural code. Could the same be done for the Māori language as already begun through the Māori Language Commission and are we right in assuming that some similar process or processes operate to preserve the codified culture incorporated into the language of New Zealand English? Both at a general and particular level, the answers we give to these linguistic questions are critical to both the survival and character of law in Aotearoa, as well as to evaluating the case for attempting to implement from abroad any specific legal transplant into our legal system. Not a single one of these introspectively linguistic issues is without critical legal consequence.

\section{CONCLUSIONS}

We close this paper by summarising the points drawn from Slavic and South Pacific experiences by which linguistic word-building and word-borrowing provide an analogue. A model can be created and perhaps even a paradigm not only for the way in which legal transplants either do or do not work, but also perhaps for some better way in which legal transplants can be made to work. 
Translation theory, whether linguistic or legal, is as much relevant to the legal endeavour, as it is for every lawyer to be a linguist. The following points may also be understood to apply to linguistic transplants:

(1) Legal transplants, whether within one and the same jurisdiction (intra-specific) or from one jurisdiction to another (inter-specific) are of far more common occurrence than are as yet recognised and given credence in comparative law.

(2) There are two sorts of legal transplants, the superficially linguistic and the deeply substantive. The superficially linguistic legal transplant is overtly concerned with introducing or re-defining words - although a deeply substantive inter-specific legal transplant may, through legislative sloganeering, turn out to be no more than superficially linguistic.

(3) Despite the clearly observable dichotomy between superficially linguistic and deeply substantive legal transplants, every substantive legal transplant is linguistic in its relying for its operation on some linguistic form, and every linguistic legal transplant, although apparently concerned only with re-defining words will bring about some either positive or negative legal effect by reason of its legal operation. Consequently, all legal transplants, rely more or less on language for their substantive effect.

(4) All legal transplants always entail for their proper function a comparative assessment of their translation process, from source to targeted destination, both in macroscopic terms of forms and functions, texts and contexts, differing cultures and world outlooks, as well as in microscopic terms concerning legal concepts, legal systems, and legal sub-systems.

(5) Despite most differences, of which there are not many that are more than incidental between the purely linguistic and the purely legal, the same principles apply to linguistic transplants as apply to legal transplants, although the normative quality of law when used to effect and enforce both superficially linguistic and substantive legal transplants will obviously have more critical consequences for their observed or unobserved outcomes as a matter of comparative law.

(6) Because of the risk factor associated with every process of linguistic or legal translation as a result of which misunderstanding, confusion, conflict, or outright repudiation can arise, a comprehensive risk factor analysis becomes a prerequisite for any proposed legal transplant no less than would be scientifically required for the biological introduction of any exotic species into an indigenous environment. 